\title{
IDENTIDAD NACIONAL Y CONVERGENCIA JURÍDICA: UN DESAFÍO PARA EL DERECHO COMPARADO
}

\author{
IGNACIO GRANADO HIJELMO \\ Doctor en Derecho \\ Profesor Asociado de Derecho Constitucional Comparado \\ Universidad de La Rioja
}

SUMARIO

I. EL CONCEPTO DE IDENTIDAD COLECTIVA Y SUS ELEMENTOS. 1. Elementos subjetivos: A) Creencia. B) Sentimiento. C) Voluntad. D) Reconocimiento. 2. Elementos objetivos: A) Tiempo. B) Espacio. C) Acervo económico. 3. Elementos Formales: A) La raza. B) La lengua. C) La religión. D) El arte, las tradiciones y otros referentes. II. EL CONCEPTO DE IDENTIDAD INDIVIDUAL Y SU DINÁMICA. 1. LAS PERTENENCIAS: UNIDAD DE IDENTIDAD Y PLURALIDAD DE REFERENTES. 2. LA PARTICIPACIÓN: RECONSTRUCCIÓN DE LA PERSONA, ALTERIDAD Y SENTIDO DEL DERECHO. III. IDENTIDAD Y DEMOCRACIA: ALGUNAS SOLUCIONES. 1. LA INSTITUCIONALIZACIÓN DE LOS CÍRCULOS CONCÉNTRICOS DE COMPETENCIAS IDENTITARIAS. A) La teoría de los círculos concéntricos. B) La técnica de la institucionalización de las identidades. 2. LA CENTRALIDAD RADICAL DE LA DIGNIDAD Y LOS DERECHOS HUMANOS.

\section{RESUMEN}

En el presente trabajo se analizan los conceptos de identidad en sentido colectivo e individual a la luz de la moderna filosofía y ciencia política; se analizan sus distintos componentes subjetivos, objetivos y formales, la dinámica y patología de los mismos y se reflexiona sobre sus consecuencias con vistas a sus posibilidades de construir una 
convivencia pacífica en democracia sobre la base de una visión personalista y comunitaria del hombre y la sociedad como realidades sistémicamente organizadas en círculos concéntricos de competencias en torno a una idea de radical centralidad de la dignidad y los derechos humanos.

\section{EL CONCEPTO DE IDENTIDAD COLECTIVA Y SUS ELEMENTOS}

Identidad, etimológicamente, deriva de idem que, a su vez, procede de is-dem, donde dem es un sufijo de insistencia que significa éste precisamente . Sin embargo, semánticamente, el concepto de identidad es mucho más complejo. El propio Diccionario de la Real Academia de la Lengua ofrece varias acepciones que remiten a diversos árboles de conceptos ${ }^{1}$. Esta multiplicidad de significados lleva a pensar que la identidad no es un concepto unívoco, sino analógico -en la terminología del pensador riojano Gustavo Bueno, un categorema con analogía de atribución-, esto es, con muy diversos significados según el contexto ${ }^{2}$. De ahí que, más que por el concepto que la identidad pueda tener en otros ámbitos, comenzaremos interrogándonos por el que tiene en Ciencias Sociales y Teoría Política donde aparece como identidad colectiva.

Entiendo por identidad en sentido colectivo "la creencia, sentimiento y voluntad socialmente compartidos y reconocidos que un grupo social organizado manifiesta de existir como una comunidad territorial, diacrónica y titular de un propio acervo económico y cultural”.

Existen dos tendencias contrapuestas en orden a la caracterización de la identidad en sentido colectivo ante la Ciencia Política. Por un lado, quienes sostienen que la identidad revela las raíces más profundas de la persona y la convivencia humanas por lo que resulta fundamental para comprender la esencia de las naciones, la génesis y dinámica de los Estados, los movimientos nacionalistas, así como muchas instituciones sociales y políticas. Por otro, los que, alarmados por los tremendos excesos e incluso matanzas a que la identidad ha conducido en el pasado y también en nuestros días, piensan que se trata de un concepto que debemos olvidar cuanto antes para sustituirlo por una visión universalista del hombre, de la historia y de la sociedad que asiente todo proyecto de convivencia política civilizada sobre la base de un imperio generalizado de los derechos humanos.

Ante esta disyuntiva de posturas, muchas veces polarizadas en torno al binomio nacionalismo - antinacionalismo, estimo que procede una serena reflexión de los aspectos positivos y negativos de este peculiar concepto politológico que es la identidad ya que estoy persuadido de que ambas posturas encierran no pocas verdades, pero también incurren fácilmente en excesos teóricos que luego se traducen en auténticos problemas irresolubles en la práctica. Por eso, no me preocupa desde estas líneas hacer

${ }^{1}$ Así el DRAE ofrece como una de sus acepciones la de "cualidad de idéntico", es decir, de aquello "que es lo mismo que otra cosa con la que se compare", pero también recoge la acepción que denomina "jurídica" consistente en "el hecho de ser una persona o cosa la misma que se supone o busca" y otra de tipo matemático cual es "la igualdad que se verifica siempre cualquiera que sea el valor de las variables". Pero, en realidad, hay muchos otros significados de identidad, pues en la vida ordinaria se emplea como sinónimo de igualdad, cohesión, inclusión, participación, pertenencia, unidad y otros muchos que, además, son distintos en cada ámbito (el Derecho, la Medicina, las Matemáticas, etc).

${ }^{2}$ BUENO, Gustavo, "Los predicables de la identidad", en El Basilisco, Oviedo, número 25, Enero-Marzo, 1999. 
análisis intelectualmente tan avanzados como utópicos, cuanto tratar de sentar las bases para un examen desapasionado de los distintos aspectos del problema de la identidad con vistas a poder aportar soluciones prácticas para una vida personal, social y política en paz sin incurrir en fáciles reduccionismos.

Pero comencemos ya analizando los distintos elementos que se desprenden del concepto de identidad que hemos propuesto y que podemos sistematizar en: Subjetivos (la creencia los sentimientos, la voluntad, el reconocimiento), objetivos (el tiempo, el territorio, la economía) y formales ( los valores compartidos, la cultura, la raza, la lengua, la religión, el arte, las tradiciones). Luego explicaré la razón de incluir la lengua y la raza entre los elementos formales y no entre los objetivos.

\section{ELEMENTOS SUBJETIVOS}

Hemos incluido entre los elementos o componentes de carácter subjetivo de la identidad colectiva, la creencia, sentimiento y voluntad en que consiste, así como el reconocimiento social que precisa.

\section{A) Creencia}

Nuestra descripción del concepto de identidad comenzaba con la idea de creencia y tal es el primero de los elementos subjetivos de la misma porque, a mi entender, la identidad es prioritariamente una "res mentis", no una "res entis", es decir, que no se refiere a una realidad en el sentido ontológico y sustancial, sino a una realidad puramente intelectual y de conocimiento. Concretamente hemos de caracterizarla como una certeza en sentido riguroso. Esto significa que no pertenece al estatuto gnoseológico de las verdades, esto es, de lo que "es así" en la realidad, sino al de las certezas, o sea, de lo que "creemos que es así" 3 .

Ello significa que si, adoptando una terminología médica, analizamos la etiología de la identidad, nos encontramos siempre una previa operación de concienciación o toma de conciencia que supone conocer los referentes identitarios y asumirlos como propios, una labor que suele ser realizada por una élite minoritaria motivada o incluso por un ideólogo que opera como conductor de conciencias (psicopompo) o generador de mitos (mistagogo).

Ahora bien, la lógica de la creencia puede conducir fácilmente a generar una comunidad de creyentes que pueden terminar en una patología de la identidad si pretenden transformar su certeza en verdad, incluso en la única verdad y convertir así este elemento identitario en excluyente de cualquier otro, dando lugar al fundamentalismo radical nacionalista que puede incluso degenerar en una identidad asesina en el sentido de Amín Malouff ${ }^{4}$.

En ese sentido, tiene razón P. Gómez García cuando afirma: “(Desarrollemos la conciencia y el sentimiento de pertenencia a la especie humana y seremos todos una

\footnotetext{
${ }^{3}$ Cfr. WITTGENSTEIN, Ludwig, Sobre la certeza, Madrid, Gedisa, 1987: ALEJANDRO, Jose María de, Gnoseología de la certeza, Madrid, Gredos, 1965.

${ }^{4}$ MAALOUF, Amín, Las identidades asesinas, Madrid, Alianza, 1999.
} 
sola etnia!" 5 . Sin embargo, mientras eso no ocurra, es evidente que, en su anatomía actual, la identidad demuestra que consiste sólo en una idea, pero en el bien entendido de que ello no desvaloriza en su absoluto su posible eficacia ya que, politológicamente, las ideas son, para empezar, nada más y nada menos, que ideas, con todo lo que ello significa de potencial motor de la humanidad. Además, por ser precisamente una idea, forma parte de los elementos politológicos, ya que las ideas, junto a los sentimientos y los intereses, son uno de los tres grandes estímulos y motores de la acción política, tanto de los gobernantes como de los gobernados.

En suma, la vida política está hecha, más que de verdades, de creencias y, por eso, es importante someter nuestras propias creencias políticas, como son las relativas a la identidad, a una crítica racional que permita pulir todos sus excesos y reconducirla hacia una convivencia civilizada donde, junto al necesario respeto a esas creencias, se levante un serio muro de objeciones cada vez que el desarrollo de las mismas pueda lesionar el contenido actual de los derechos humanos.

\section{B) Sentimiento}

Un segundo elemento subjetivo de la identidad es el sentimiento. Alude a este elemento la conocida expresión "bucle melancólico" con la que Jon Juaristi titula una de sus más conocidas obras sobre el nacionalismo vasco ${ }^{6}$. En efecto, la identidad es también una "res cordis", una realidad sentimental pues opera sobre un sustrato de afectividad.

El sentimiento constituye a quienes lo comparten en una comunidad, entendida esta última como Gemeinschaft, esto es, un grupo social estructurado sobre una base de solidaridad y cooperación leal, a diferencia del modelo impersonal y meramente competitivo representado por la idea de sociedad (Gesellschaft) ${ }^{7}$. Este sentimentalismo romántico enlaza así con las ideas hegelianas del espíritu popular preconizadas por la Escuela Histórica y se nutre de los que Mircea Elíade denomina mitos genéticos, es decir, las narraciones mitológicas que aparecen para explicar popularmente los orígenes de un grupo sentimental ${ }^{8}$.

El componente sentimental de la identidad se traduce en la construcción de un arquetipo comunitario ideal, "el pueblo", pero, atención, pese a su apariencia comunitaria e integradora, en realidad se trata de una idea excluyente ya que se refiere sólo al "verdadero pueblo" que es el único sujeto de la identidad, por lo que en este concepto no resultan comprendidos quienes no participan de esos sentimientos, aunque vivan dentro de las mismas fronteras y habiten en la casa de al lado. Se trata, pues, de un con-

${ }^{5}$ GOMEZ GARCIA, Pedro, "Las desilusiones de la identidad: La etnia como subconcepto", en Idem (coord.), Las ilusiones de la identidad, Frónesis-Cátedra-Universidad de Valencia, Madrid, 2000, pág. 43.

${ }^{6}$ JUARISTI, Jon, El bucle melancólico, historias de nacionalistas vascos, Madrid. Ed. España, 1997.

${ }^{7}$ Cfr. MORIN, Edgar, “Identidad nacional y ciudadanía”, en Gómez García, Pedro (coord.), Las ilusiones de la identidad, op. cit., pág. 18.

${ }^{8}$ ELÍADE, Mircea, Mito y realidad, Barcelona, Labor, 1991. Este fenómeno ha sido desvelado en diversos pueblos europeos por JUARISTI, Jon, El bosque originario, Madrid, Taurus, 2000. 
cepto que, aparentando ser democrático e incluso profundamente popular, en rigor atenta contra la lógica inclusiva de la democracia que ha resaltado Habermas ${ }^{9}$.

Desde luego, los aspectos sentimentales de la identidad tienen y han tenido una importancia social decisiva. Piénsese, sin ir más lejos, en la aportación de los literatos, los músicos y los poetas a la comprensión profunda de las tradiciones, de las costumbres populares y del alma de pueblos y naciones. Este tipo de sentimientos forman parte del legítimo sentir de muchas gentes y su trascendencia no puede minusvalorarse en aras de un reduccionismo universalista que no resulta fácilmente accesible para muchas personas y que, además, nos privaría de valiosísimas aportaciones artísticas e intelectuales del espíritu humano.

En este ámbito sentimental se inscribe el concepto complejo e indefinible de patria que, al tildarse frecuentemente de "madre patria", mezcla los dos conceptos freudianos propios del psiquismo más elemental, los de padre y madre, para así evocar a los componentes del grupo identitario sus más íntimas raíces como "hijos" (enfants de la patrie). Ni siquiera los autores que, como Habermas, más están haciendo por desmitologizar los elementos constitutivos de la identidad colectiva y asentar la convivencia sobre bases universalistas, han podido prescindir para ello del prestigio de estos términos, como luego veremos al examinar el concepto de "patriotismo constitucional".

Pero, esto dicho, es obvio que existe también una patología de la identidad causada por este elemento sentimental, ya que la melancolía en que consiste, puede degenerar en auténticas mafias articuladas en torno a la idea emotiva de la "cosa nostra", "lo nuestro", y al monopolio de la identidad por un sector poblacional concreto ("nosotros") con exclusión de los demás, de los que, aunque vivan junto a nosotros, no son de "nuestra gente", no pertenecen al grupo de "los nuestros". Así, lo que puede iniciarse como un movimiento asociativo natural entre quienes tienen unos mismo sentimientos, puede convertirse, como ha resaltado M. Castells, en un grupo activista en favor de una identidad excluyente ${ }^{10}$.

Se impone, pues, buscar las fórmulas para que cada grupo identitario desarrolle libremente sus propios sentimientos de identidad colectiva, pero sin que tal dinámica conduzca a impedir que las demás personas y grupos hagan lo propio. Ese tipo de fórmulas se estereotipan en el respeto que todos deben mantener a los derechos humanos puesto que de otra manera no se puede fundar ningún marco de convivencia tolerante.

\section{C) Voluntad}

La identidad tiene un tercer elemento subjetivo -que también puede concebirse como una tercera fase en su formación-: la voluntad. En efecto, la identidad es también una "res voluntatis", esto es, una realidad que estriba, no tanto en un conocer, cuanto en un querer, pues no basta con que los elementos identitarios sean conocidos por la comunidad, sino que es preciso, además, que ésta los asuma como propios.

${ }^{9}$ HABERMAS, J., La inclusión del otro, estudios de teoría política, Barcelona, Paidos, 1999. pag. 23. Cfr. a este respecto las acertadas observaciones de PEREZ TAPIAS, J.A. en ")Identidades sin fronteras?. Identidades particulares y derechos humanos universales”, incluido en Gómez García, P. (coord.), Las ilusiones de la identidad, op. cit., pág, 84, especialmente nota 62.

${ }^{10}$ Cfr. CASTELLS, M., La era de la información. Economía, sociedad y cultura, vol. 2, El poder de la identidad, Madrid, Alianza, 1998. 
En esta fase, la identidad experimenta una trasmutación política ya que, de ser una idea meramente intelectual, se convierte en una idea-fuerza, en un impulso de la voluntad y en un movimiento de ésta hacia la acción.

Cuando la identidad queda trascendida por la voluntad, se pr oduce una intens ificación del fenómeno identitario que, fecundada por este elemento volitivo, se potencia y eleva al rango de voluntad nacional. Ello ocurre cuando la comunidad no se contenta con conocer y sentir su identidad, sino que da un paso más, la asume y desea realizarla, esto es, realizarse como una opción política auto-reflexiva que la consagra como Nación.

El "Pueblo", iluminado por la creencia de su identidad y confort ado por el se ntimiento de la misma, se convierte así en "Nación" cuando añade la fuerza de la voluntad, una voluntad que, a través de la auto-determinación política y la adición de los elementos objetivos de la identidad (sobre todo el espacio -la tierra- y el tiempo -la historia-), puede convertirse en una verdadera voluntad soberana sobre la que crear y edificar un nuevo Estado ${ }^{11}$.

De esto puede derivar, por supuesto, una patología bien conocida: el nacionalismo. El nacionalismo surge cuando el grupo identitario no se contenta ya con predicar, amar y querer la propia identidad, sino que trata de elevarla constantemente de rango político hasta convertirla en Nación y así en fundamento de un Estado uninacional. La patología del fenómeno estriba principalmente en esta última característica ya que el Estado preconizado por el nacionalismo es un Estado del que quizá queden excluidos los que carezcan de los signos de identidad del grupo y, por tanto, es un Estado que corre en peligro de asumir como tarea prioritaria la limpieza, sea étnica, religiosa o política, según el elemento identitario que más se exagere o magnifique.

No extraña así que los Estados uninacionales surgidos en la Europa del s. XVI se hayan construido en buena medida sobre la base de expulsiones o conversiones forzosas de los grupos étnica o religiosamente disidentes y minoritarios. Por eso, la moderna evidencia de que la convivencia pacífica se asienta sobre la necesidad de construir Estados plurinacionales ${ }^{12}$, es decir, Estados con capacidad de institucionalizar en su seno diversas naciones e identidades colectivas, nos hace, por un lado, aborrecer las operaciones de limpieza identitaria que se han practicado en algunos nacientes Estados uninacionales, y, por otro, padecer las críticas de los nuevos nacionalismos cuando nos recuerdan que nuestros propios Estados nacionales europeos surgieron en el s. XVI merced a operaciones parecidas de "limpieza" de grupos étnicos o religiosos disidentes. Y es que las críticas no pueden formularse sino desde actitudes sinceras de arrepentimiento y petición de perdón.

La reacción contra los excesos del nacionalismo y los Estados uni-nacionales ha llevado a autores como Habermas, partiendo de la lógica inclusiva y no excluyente de toda verdadera democracia, a preconizar como único legítimo un radical "patriotismo

${ }^{11}$ Cfr. RUBERT DE VENTÓS, X., De la identidad a la independencia: la nueva transición, Barcelona, Anagrama, 1999.

${ }^{12}$ Decimos necesidad porque nos parece obvio que, habiendo miles de etnias, culturas y lenguas conocidas en el mundo, -por poner sólo el ejemplo de algunos elementos identitarios tenidos por especialmente intensos-, y además muchas veces repartidas entre diversos Estados, si todas las identidades étnicas, culturales o lingüísticas pretendiesen convertirse en naciones-estado, la comunidad internacional sería inviable en un mundo globalizado como el actual. 
constitucional" . Habermas toma esta expresión de Dolf Sternberger para -como señala Pérez Tapìas ${ }^{13}$ - trasladarla de la experiencia alemana al Proyecto de la Unión Europea, pero en el bien entendido de que dicho patriotismo se trata, no de un neo-nacionalismo de Estado uninacional integrista y excluyente de las minorías étnicas o culturales, sino precisamente de todo lo contrario, esto es, de una lealtad a los valores universales que las declaraciones constitucionales de derechos comportan en el marco de una democracia estatal integradora e inclusiva de dichas minorías.

Pero entiendo que la sugerencia de Habermas es aún más profunda, en cuanto que reivindica la idea de que los derechos humanos se defienden más adecuadamente en el marco de las Constituciones estatales y, por tanto, conforman una especial unidad con la idea de Estado constitucional de Derecho. Esta precisión nos pone en guardia frente a los reduccionismos que pretenden una visión meramente universalista de los derechos humanos de suerte que, al prescindir de las instancias estatales, pueden conducir a su esterilización práctica por falta de mecanismos de garantía eficaces. En efecto, parece preciso reconocer que, hoy en día, los derechos humanos serían muy poca cosa sin tener detrás las estructuras estatales para su reconocimiento, garantía y protección. De esta forma, derechos humanos y Estado o, si se prefiere, derechos humanos y Constitución, conforman una paridad que, por el momento, no parece sensato destruir en aras del universalismo.

Por otra parte, las fáciles críticas a la identidad no pueden conducirnos hacia una crítica radical de todos sus elementos y hacernos olvidar, por ejemplo, que el elemento identitario que ahora nos ocupa y que hemos denominado voluntad es tan decisivo que se encuentra detrás del nacimiento de muchos de los grandes Estados democráticos actuales. En este sentido, podemos afirmar que la voluntad nacional está en la base de la construcción misma del Estado y de conceptos tan importantes como la soberanía o la moderna conciencia de la defensa. Desde el punto de vista socio-jurídico, la voluntad nacional está en la raíz misma de la decisión constituyente originaria del pueblo, y entraña la misma fuerza en que la potencia constituyente consiste. En otras palabras, está en el mismo fundamento de la Constitución material de los Estados y de ahí que su trascendencia politológica sea crucial.

\section{D) Reconocimiento}

La identidad es también "res socialis" en el sentido de que las creencias, sentimientos y voluntad en que consiste, no basta con que las tenga una persona individualmente considerada y sólo ella ${ }^{14}$, sino que deben ser ampliamente compartidos por un

\footnotetext{
${ }^{13}$ PEREZ TAPIAS, J.A., en ")Identidades sin fronteras?, identidades particulares y derechos humanos universales”, en Gómez García P. (coord.), Las ilusiones..., op. cit, pág.86

${ }^{14}$ Aunque, en su origen, la idea nacionalista puede derivar de una sola persona y de un núcleo de discípulos que integran la élite motora de la concienciación nacional. La idea subyacente en el mesianismo estriba precisamente en la creencia de que las verdaderas esencias del pueblo elegido por la divinidad desde el comienzo de los siglos para un destino trascendental fueron perdidas por todos los componentes de ese pueblo, salvo, milagrosamente, por un salvador, un único personaje -por supuesto, luego mitificado o divinizado-, que las reasume y resume y que, con su sacrificio personal, devuelve su vigor a aquellas esencias verdaderas, refunda al pueblo y lo repone en su camino glorioso. Cfr. ALONSO ÁVILA, A., El mesianismo en el cristianismo antiguo y en el judaísmo, Universidad de Valladolid, Valladolid, 2000. De ahí que los líderes nacionalistas tiendan a considerarse unos iluminados por la divinidad para rescatar al
} 
grupo o categoría social, pero con el añadido de que va a ser precisamente ese grupo o categoría quien debe reconocer como integrante de la comunidad a cada persona que pretenda tener las creencias sentimientos y voluntad que conforman la identidad comunitaria correspondiente.

Pero conseguir este reconocimiento no es tan fácil como adquirir un carnet de identidad por mera residencia. El carnet identitario del nacionalismo no es tan automático e individualista. Por el contrario, es concedido "ad personam" por la comunidad pues consiste en un reconocimiento derivado de la idea de que la identidad se refiere, no a una sociedad impersonal de hombres individuales regida por criterios fríos y automáticos como la mera residencia, sino una comunidad unida por lazos afectivos mucho más complejos. Por ello, como en los clubes exclusivos, no basta con querer pertenecer a la comunidad identitaria, sino que hay que poder pertenecer a ella y, para ello, es preciso ser admitido mediante este reconocimiento social.

Así pues, la génesis de la identidad pasa primeramente por una fase de "comunitarización" en la cual las ideas y sentimientos identitarios son ampliamente difundidos y compartidos en el seno del grupo que se auto-define como identitario, pero enseguida entra en una fase de aceptación donde la comunidad generada por esas ideas y sentimientos compartidos ha de reconocer como miembro al que pretenda compartirlos. Esta doble dinámica comunitaria explica que algunos movimientos identitarios se autodenominen como una verdadera "Comunión".

Este mecanismo bifásico de la génesis identitaria explica el deseo que las minorías marginadas en el sistema desarrollan por hacer méritos con objeto de que los mismos sean reconocidos y así integrarse en el grupo comunitario que está en fase de formación o afirmación ${ }^{15}$. De ahí que las propuestas más anti-nacionalistas postulen una reconsideración de la nacionalidad como fuente de un estatuto privilegiado de derechos en comparación con el de los extranjeros meramente residentes y a sustituir los mecanismos de adquisición de la nacionalidad por meras constataciones de residencia durante un determinado periodo de tiempo.

Este tipo de propuestas tienden a una realización radical de la democracia inclusiva y, por ello, son bien vistas por los partidarios del acogimiento de inmigrantes. Sin embargo, plantean evidentes problemas prácticos desde el punto de vista cuantitativo para los países de acogida y, por lo que ahora nos interesa, también desde la perspectiva de la preservación de la identidad nacional, por lo que este punto se anuncia como especialmente conflictivo en un futuro a medio plazo. El problema es importante porque repárese en que ahora ya no estamos hablando de la identidad de grupos infraestatales con respecto al Estado, sino de la identidad del mismo grupo estatal. Por eso, los partidarios de estas propuestas terminan postulando una redefinición global del Estado para no apoyarla en una base nacional, es decir, en una identidad concreta, sino en un estatuto jurídico determinado por el respeto constitucional a los derechos humanos de todas las personas, grupos e identidades.

pueblo lacerado por las humillaciones y el olvido de su propia grandeza y a considerarse a sí mismos en los momentos de persecución como verdaderos mesías sufrientes.

${ }^{15}$ Es el caso del bien conocido fervor de los conversos o de la paradoja del judío alemán en la época nazi que podía sentirse perfectamente alemán pero no era reconocido como tal por la comunidad política dando lugar a la segregación e incluso a la eliminación étnica o religiosa y política. 
En mi criterio, como luego apuntaré, se impone una formula intermedia, de suerte que la centralidad de los derechos fundamentales y de lealtad constitucional no impida ni deslegitime la existencia y desarrollo de comunidades identitarias en los diversos niveles de círculos concéntricos en que debe organizarse la convivencia humana civilizada, uno de los cuales es, sin duda, el estatal ${ }^{16}$.

\section{ELEMENTOS OBJETIVOS}

Una vez expuestos sucintamente los elementos subjetivos, podemos adentrarnos a describir los componentes de tipo objetivo de la identidad colectiva, como son el temporal,el espacial y el económico.

\section{A) Tiempo}

Entre los elementos objetivos de la identidad destaca el tiempo. El factor tiempo resulta trascendental en la génesis identitaria puesto que la identidad es esencialmente diacrónica, es decir, remite a una comunidad de origen y a una memoria histórica que, plasmada en una identidad presente, se proyecta hacia el futuro como una comunidad de destino ${ }^{17}$.

El elemento temporal enlaza así la identidad con la Historia a la que convierte en elemento fundamental de la misma, hasta el punto de consagrarla como una "Santa Tradición" mediante leyendas de autoctonía y otros mitos genéticos que acaban convirtiéndola en una verdadera "Historia Sagrada".

Este elemento diacrónico se escinde, por un lado, en la que, con A. Maalouf, podemos denominar herencia vertical o legado de los padres y antepasados que la comunidad, como buen fiduciario, debe recibir, conservar, aumentar y transmitir a las generaciones venideras; $y$, por otro, en una herencia horizontal que la propia comunidad recibe del presente, es decir, de los demás hombres y del mundo actual en cuanto que nadie puede sustraerse a ser hijo de su tiempo ${ }^{18}$. La tensión actual de las identidades nacionalistas entre ambos polos se aprecia perfectamente en los programas políticos de los respectivos partidos, por ejemplo, cuando insisten en profundizar en la propia lengua, muy identitaria pero poco apta para la comunicación, y, a la vez, en el dominio de las nuevas tecnologías de la comunicación. Dicha tensión estriba en conjugar como integrante de la comunidad ambas herencias (la recibida y la actual) con una tercera, la herencia proyectiva, consistente en lo que se va a legar a generaciones futuras.

La patología que puede advenir a la identidad por razón de este elemento temporal de la misma tiende a producirse mediante un falseamiento intencional de la historia o una inexistente o falsa lectura de los signos de los tiempos que impide la adecuada actualización y puesta al día (el "aggiornamento") de la ideología identitaria, conduciéndola a una prospectiva involucionista y excluyente, es decir, reaccionaria, pues re-

${ }^{16}$ Cfr. mi obra, Reflexiones jurídicas para un tiempo de crisis, nuevo orden internacional, constitución europea y proceso autonómico español. Barcelona Ediciones Internacionales Universitarias, 1997, especialmente, Cap. V, "Horizontes de solución”, págs. 142 y ss.

${ }^{17} \mathrm{La}$ idea es de Otto Bauer. Ahora se entiende mejor aquel concepto falangista de patria como "unidad de destino en lo universal". Cfr. MORIN, E., "Identidad nacional y ciudadanía”, en Gómez García, P. (coord.), Las ilusiones de la identidad, op. cit., pág. 19.

${ }^{18}$ Cfr. MAALOUF, A., Las identidades asesinas, op, cit., pág. 125. 
accionario es todo lo que pretende reimplantar un orden social objetivamente periclitado, aun mitificándolo como una antigua edad de oro o un paraíso perdido.

De ahí la importancia que adquiere en los modernos Estados compuestos y pluriculturales el problema de la enseñanza -y consecuente vivencia- de la Historia, un debate que excede el ámbito de la organización administrativa del servicio público educativo para inscribirse entre los factores identitarios. Con arreglo a mi criterio -que luego explicitaré- de que la identidad se estructura en círculos concéntricos, estimo que debe enseñarse y asumirse la Historia que afecta a todos y cada uno de los distintos círculos identitarios (mundial, internacional, europeo o continental, estatal, regional o infraestatal, local, etc). Esto debe hacerse de forma que, sin mixtificaciones ni falseamientos, se conserve la idea de las distintas identidades, junto a sus recurrentes e innegables relativizaciones a lo largo del tiempo. Todo ello, además, con una visión diacrónica, es decir, sin eludir la profundidad histórica con arbitrarias periodificaciones o restricciones. Esto implica permitir siempre una visión sistémica y general de cada círculo identitario que permita siempre la perspectiva recíproca de los demás. En suma, una Historia holística, no parcial, y conducida a una permanente tensión sistémica entre el círculo identitario de que se trate y los demás, desde los locales hasta los universales.

\section{B) Espacio}

El territorio, "la tierra" y, en general, el elemento espacial resulta determinante de la identidad porque ésta supone una territorialidad en cuanto que la comunidad se auto-identifica precisamente por su implantación en una tierra propia en la actualidad o bien en una tierra de nuestros padres que la comunidad ocupó o poseyó en el pasado, o incluso en una tierra prometida en virtud de algún mito genético y que se espera recuperar en el futuro.

La antigua aprissio o pressura de tierras yermas de la que nos hablan los textos altomedievales castellanos no es sino el trasunto de la ocupación como medio originario de adquirir en dominio en Derecho romano que ha pasado a nuestros Códigos Civiles. Sin embargo, cuando este fenómeno no es individual sino grupal, se convierte en poblamiento o asentamiento de una población en un espacio. La necesidad y conveniencia de afirmar aquella ocupación originaria explica que la misma suela consagrarse mediante mitos genéticos que elevan el territorio a la categoría de Tierra, y una Tierra Santa, como se aprecia en los casos de Rusia o Palestina que han convertido tales expresiones en paradigmáticas.

Este elemento se traduce en una delimitación del espacio. En efecto, el grupo ocupante anuda al poblamiento consecuencias de Derecho Público consistentes básicamente en el trazado de fronteras que delimitan el ámbito de ocupación. Obviamente, ello requiere el consentimiento expreso o tácito de los grupos vecinos que muchas veces ha debido ser arrancado tras cruentas guerras, como ha recordado recientemente Sánchez Ferlosio ${ }^{19}$ Esto revela que la fijación de fronteras es una cuestión que excede a la competencia exclusiva de la comunidad interesada, ya que es un problema de Geopolítica y depende de las pretensiones iguales de otras comunidades aledañas, por lo que es una cuestión que afecta a la comunitas gentium y, por tanto, es de Derecho Internacional

${ }^{19}$ SANCHEZ FERLOSIO, Rafael, La hija de la guerra y la madre de la patria, Madrid, Destino, 
Público. Sin embargo, los movimientos identitarios han promocionado frecuentemente la muy discutible -y potencialmente explosiva- idea de que existe un espacio natural -en último término, un "espacio vital" (Lebesraum)- de toda comunidad (aunque sólo se suele defender con ardor respecto a la propia) en el sentido de que cada una tenga derecho (natural) a ocuparlo. Planteada así como una cuestión de Derecho Natural, es decir, de Geo-dierética, el problema de la distribución del territorio queda sustraído al ámbito de la Geopolítica y, por tanto, del Derecho Internacional Público ${ }^{20}$.

En todo caso, me parece evidente que cualquier plasmación práctica en este sentido requiere diálogo y consenso para convenir espacios y fronteras porque, en caso contrario, las afirmaciones apriorísticas están fatalmente abocadas a una cruenta lucha para defender las que se consideran naturales, una lucha que puede ser consagrada como Guerra Santa o Cruzada, si se enfoca en la defensa de una tierra que previamente se ha reputado Santa.

Por eso, las propuestas universalistas tendentes a considerar que "el mundo es de todos los humanos" deben aceptarse, a mi juicio, sólo en cuanto se refieran al círculo competencial de ámbito mundial, esto es, sin perjuicio de los asentamientos poblacionales tradicionalmente existentes sobre círculos de ámbito más reducido y siempre bajo un prisma de consenso y convenio ya que, de otra forma, tales ideas no son sino semillero seguro de guerras y conflictos de todo tipo.

\section{C) Acervo económico}

Denomino convencionalmente acervo económico al conjunto de elementos naturales, materiales, objetivos y formales que conforman la estructura y fuerza económica de una comunidad organizada, comprendiendo desde sus recursos primarios, hasta su grado de industrialización o terciarización, su productividad, su competitividad o su cultura empresarial, así como el conjunto de oportunidades y economías externas generadas por todo ello, es decir, lo que genéricamente podemos denominar su potencia económica global.

Pues bien, el acervo económico es también muy importante en la formación de la identidad porque la estructura económica de una comunidad determina su mayor o menor grado de desarrollo, y dicho grado determina, a su vez, no sólo su mayor o menor potencial económico y social, sino también el grado de satisfacción o frustración de la propia comunidad.

Este elemento -perteneciente, pues, tanto a la Economía como a la Psicología social-, enlaza con los intereses, otra de las grandes guías, junto a las ideas y los sentimientos, de la acción política. En efecto, son los intereses económicos los que prioritariamente explican el poblamiento, la convivencia y el trabajo de toda comunidad para alimentarse, protegerse y progresar en lo material.

Una comunidad identitaria se muestra orgullosa de su potencia económica global, de sus productos y sus empresas (una actitud claramente perceptible, por ejemplo, en la mentalidad patriótica estadounidense), lo mismo que una debilidad estructural en este campo puede conducir a un sentimiento de frustración o inferioridad (que varios

${ }^{20}$ Así lo sugiere D=ORS PEREZ-PÈIX, Álvaro., El Derecho y el sentido común; Siete lecciones de Derecho Natural como límite del Derecho positivo, Madrid, Cívitas, 1999. 
autores aprecian, por ejemplo, en los países denominados del Tercer Mundo, en especial los que estuvieron dirigidos por civilizaciones antaño poderosas, como la islámica).

Es cierto que el elemento económico cuando enlaza, por trasposición, con otros factores de identidad, como la cultura, el arte o las tradiciones autóctonas, puede producir un interesante y enriquecedor renacimiento de sectores económicos como el de los productos típicos, la artesanía o la industria y el comercio ligados al turismo, pero no menos cierto es que la dinámica del acervo económico como factor de identidad puede generar también unas relaciones de dominación hegemónica y de frustración humillante que vemos detrás de muchos conflictos nacionalistas y que explica también la conexión entre ciertos grupos identitarios radicalizados y grandes fortunas o flujos internacionales de dinero blanqueado o de procedencia dudosa, formando a veces verdaderas redes financieras.

Este elemento plantea directamente el problema de la riqueza y la pobreza y de las injustas desigualdades a todos los niveles existentes en esta materia. No cabe duda de que la actual situación mundial al respecto, con millones de desheredados y continentes completos al margen del desarrollo, requiere una respuesta urgente y eficaz desde todos los círculos competenciales y sus respectivos ámbitos de actuación (mundial, internacional, continental, estatal, etc). Los derechos humanos requieren, con carácter general, asegurar un nivel de subsistencia cuya preservación debe primar sobre toda consideración identitaria inferior. En este sentido, el concepto de alimentos, como enseña el Derecho de Familia, no sólo comprende lo necesario para comer y beber, sino también para una sanidad básica y una educación elemental. Mientras este problema no esté adecuadamente resuelto, penderá un estigma de ilegitimidad sobre todas las identidades que pretendan construirse sobre la base de un acervo económico excluyente.

\section{ELEMENTOS FORMALES}

Los elementos formales de la identidad se reconducen a valores ampliamente compartidos por la comunidad identitaria y que suelen resumirse en la idea de cultura. Ahora bien, el término valores está muy prestigiado en el uso corriente porque parece aludir a cualidades espirituales positivas desde el punto de vista moral, sin embargo aquí lo empleamos sin connotaciones morales, es decir, incorporando también lo que desde una perspectiva ética pudieran calificarse como disvalores ya que tanto unos como otros nos interesan siempre que tengan eficacia en orden a crear o fortalecer un sentimiento o creencia de identidad. Esto justifica, por ejemplo, tratar entre los elementos formales de la identidad aspectos tales como la raza o ciertas costumbres y tradiciones cuya dinámica puede presentar aspectos inmorales e incluso contrarios a los derechos humanos.

Esto dicho, la mayor parte de los elementos formales de la identidad se resumen en valores reconducibles a la cultura. Ahora bien, si existe una palabra con significado amplio en nuestro diccionario, desde luego, esa es cultura. Sin duda la cultura - entendida en su más amplio sentido como conjunto de conocimientos, valores y elementos intelectuales, estéticos y morales compartidos por una comunidad- constituye uno de los componentes esenciales de toda identidad colectiva, pero encierra diversos elementos en su seno. 
Habida cuenta, pues, de sus múltiples componentes identitarios, prefiero emplear, como en el caso de la economía, el término "acervo cultural" para referirme a los mismos, pero con la importante precisión de que no todos los componentes de la cultura integran el acervo cultural a efectos identitarios, sino sólo aquéllos que contribuyen a constituir o reforzar la creencia y sentimiento de una identidad colectiva. Por ejemplo, los conocimientos científicos generales son comunes a tantas colectividades humanas que, si bien son esencialmente culturales, no pueden considerarse patrimonio de una "cultura" identitaria concreta. Pues bien, centrándonos exclusivamente en los elementos culturales que tienen relevancia identitaria es forzoso reconocer, a su vez, que son también muy variados, si bien, ciñéndonos a los más revelantes, podemos cifrarlos en la raza, la lengua, la religión, el arte y las tradiciones propias del grupo identitario.

\section{A) La raza}

El de raza es uno de los conceptos más intuitivos y, sin embargo, más difíciles de definir. Se habrá observado que, por nuestra parte, no hemos dudado en incluirlo entre los elementos formales de la identidad. Actuamos así, habida cuenta de las aberraciones cometidas en nombre del mismo y porque somos conscientes de la trascendente influencia que el aspecto cultural tiene en nuestra idea de raza. Tan es así, que muchos antropólogos modernos postulan sustituir el concepto de raza por el menos $r a-$ cial y más cultural, de etnia, buscando con el eufemismo de este sinónimo huir del desprestigio evidente en que ha incurrido el clásico concepto de raza.

Así, las modernas definiciones del concepto de raza ${ }^{21}$ son bien significativas de la absoluta relatividad del mismo desde el momento en que la caracterizan como un sistema abierto, episódico y muy influido por aspectos fenotípicos, esto es, culturales, y por múltiples variables que imposibilitan clasificaciones exactas $\mathrm{y}$, mucho menos, censos poblacionales subsiguientes.

Por ello, insisto en mi criterio de que la raza no debe considerarse un elemento objetivo sino formal de la identidad. Es ahora el momento de explicar esta opción, que no sólo es metodológica. La raza parece constituir un hecho objetivo: las personas tienen distintos caracteres étnicos y resulta evidente que es distinto el color de su piel, su grupo sanguíneo y sus rasgos físicos o somáticos. Sin embargo, es muy difícil, por no decir imposible, delimitar científicamente un grupo étnico ()en base a qué variables determinarlo? y, fijadas algunas, )por qué no acudir a otras que incluirían o excluirían a ciertas personas?) ${ }^{22}$. De ahí que, pese a su evidente objetividad externa, haya que estimar a la raza como un componente meramente formal de la identidad colectiva. En efecto, es la propia comunidad identitaria quien delimita su propio concepto de raza a estos efectos eligiendo algunos caracteres étnicos para atribuirles consecuencias iden-

${ }^{21}$ Por ejemplo, el antropólogo Arturo Vallés define la raza como "taxón subespecífico de Homo Sapiens constituido por un conjunto de grupos mendelianos que integran sistemas biológicamente abiertos, móviles, autodomesticables, evolutivamente episódicos y que comparten ciertos alelos a frecuencias distintas de las de otros grupos similares, debiendo sus rasgos ecotípicos a presiones selectivas que actúan en los ambientes característicos de los biomas que ocupan y del genero de vida que practican". Citado por GOMEZ GARCIA, Pedro, "Las desilusiones de la identidad: La etnia como seudoconcepto", en , Las ilusiones de la identidad, op. cit., pág. 34.

${ }^{22}$ Cfr. GOMEZ GARCIA, Pedro (coord), "Las ilusiones..., la etnia como subconcepto", op. cit., con abundante bibliografía sobre la materia, cfr. págs 124-126. 
titarias y, por tanto, determinantes de los fenómenos grupales de integración y exclusión. Esta es otra de las razones por las que el neorracismo identitario prefiere emplear el término etnia que resalta más los aspectos culturales y de antropología social que los exclusivamente biológicos.

En esta línea de suavización del concepto y consecuencias identitarias de la raza en que se mueve el neorracismo, surgen como factor identitario las estructuras del parentesco, recabándose del prestigio antropológico y etnográfico que Durkheim confirió a la materia. La genealogía reaparece así en la forma -aparentemente inocente- de la identificación de los apellidos usuales en el grupo identitario, pero, en realidad, se trata de remitir a unos antepasados comunes y, en suma, a una pretendida unidad racial originaria. Sabidas son las funestas consecuencias discriminatorias a que condujo la manía genealógica en el pasado histórico español con instituciones tan contrarias al moderno concepto de derechos humanos como las probanzas de hidalguía o los estatutos de limpieza de sangre, como para legitimar en el presente estas vanas intentonas que, además, ya fracasaron en el pasado ante el vano intento de lograr una pureza racial que genealógica y biológicamente es imposible.

Esta actitud grupal revela que la raza se comporta como un elemento formal de la identidad ya que lo relevante no es tanto la raza en sí cuanto la consideración que el grupo identitario hace de la misma y ello varía notablemente en función de las coordenadas espacio-temporales. En efecto, los grupos dominadores han menospreciado históricamente las razas de los dominados, pero muchas veces se han cambiado los papeles y los ayer dominados se convierten hoy en dominadores o los que son dominados en un espacio concreto, son dominadores en otro distinto. Por eso, lo que me parece relevante no es la raza o etnia en cuanto tal, sino que unos y otros la reputan como signo evidente de su identidad grupal, sea ésta dominante o marginada ${ }^{23}$.

Centrado así el asunto, es claro que se trata de un problema de inversión de valores ya que no estriba tanto en que cada grupo identitario valore su propia raza como elemento de su propia identidad, cuanto en que ese sentimiento valorativo se traduzca en una discriminación para con los de razas o etnias distintas. En ese mismo momento, el elemento formal de identidad en que la raza o etnia consiste se transforma en una idea con la fuerza de los disvalores y choca frontalmente con la concepción generalmente aceptada de los derechos humanos -que antropológicamente se basa en una concepción unitaria del pilum evolutivo en que la especie Homo Sapiens consiste-, pudiendo ocasionar en sus manifestaciones más extremas y patológicas aberraciones como la segregación racial, la limpieza étnica o el genocidio. Lo que sucede es que esa valoración de la propia raza ha estado tan históricamente ligada a los fenómenos de discriminación que, desde la perspectiva de los derechos humanos, se presenta prácticamentecomo un disvalor en sí misma.

Con esta apelación a los derechos humanos y a su fundamentación antropológica adelanto una idea que me parece crucial en esta materia y sobre la que volveré al tratar de la lengua y, sobre todo, de la religión, y es que la ética de tolerancia que se desprende del reconocimiento primario y radical de la dignidad de la persona humana y de los derechos que tiene en cuanto tal, conforma un corpus moral que debe imponerse

${ }^{23}$ También existe un "orgullo" de las identidades marginadas, como demostró en los años mil novecientos setenta el movimiento del black power en los Estados Unidos o más recientemente los colectivos que agrupan minorías de orientación sexual. 
a cualquier consideración o elemento identitario por respetable, histórico o tradicional que se presente.

\section{B) La lengua}

La posesión de una lengua propia constituye un factor esencial de la identidad ya que se puede vivir sin otros elementos, por ejemplo, pobremente o sin religión, pero no sin comunicarse. Es, pues, obvio que este elemento deriva de la misma naturaleza racional y social del hombre que le permite formarse un universo simbólico de ideas y representaciones, formalizarlo a través de signos y palabras, le impele y exige a comunicarse a través de las mismas con sus semejantes y a entablar con ellos diálogos y relaciones sociales de todo tipo. Sin embargo, la lengua no se comporta sólo como un elemento semiótico o instrumento comunicacional, sino que se incardina claramente en el acervo cultural de la comunidad identitaria. Ello es debido a que la lengua, como ha observado agudamente A. Maalouf, presenta a estos efectos un doble carácter: es medio de comunicación, pero, por otra parte, es también un factor de identidad ${ }^{24}$.

En el primer sentido, la lengua no es de por sí un elemento excluyente, como la religión, por cuanto pueden hablarse simultáneamente varias lenguas, pero no parece posible tener a la vez y sinceramente distintas religiones. Además, en cada medio social dado tenderá a imponerse como lengua de comunicación la que tenga un mayor potencial comunicador.

Sin embargo, ahora nos interesa la lengua como factor de identidad. Esta distinción entre lengua de comunicación y lengua de identificación resulta esclarecedora para entender que ciertos grupos identitarios empleen su propia lengua, no tanto para pretender una comunicación, cuanto para afirmar ante los demás la propia identidad. Este empleo de la lengua como factor de identidad explica la paradoja de que, en tal caso, se emplea la lengua, no para comunicarse y entenderse con el mayor número posible de personas, sino precisamente para que los demás ajenos al grupo identitario no nos entiendan y así producir el efecto reflejo de cohesionar la identidad del propio grupo lingüístico. Es más, el grupo identitario radical no quiere en realidad que los ajenos al mismo aprendan la lengua identitaria y su política lingüística va dirigida más bien a mantenerla y fomentarla entre su propio "pueblo" que a extenderla entre extraños al mismo.

Este planteamiento, unido a la sensación babélica que introduce la multiplicidad de lenguas existente en la humanidad, ha inducido a muchos pensadores universalistas a la búsqueda de un lenguaje de comunicación universal ${ }^{25}$. Sin embargo, en su sentido identitario, la propia lengua constituye un derecho humano, el de libertad lingüística, por el que no puede prohibirse a nadie a usar su propia lengua o imponer otra, de suerte que todas deben protegerse y conservarse como elementos culturales de sus respectivas comunidades ${ }^{26}$. Esta constatación requiere, pues, una regulación convencional de las lenguas y de los mecanismos de traducción para impedir el imperialismo o colonialismo lingüístico y la marginación o silencio de las lenguas minoritarias, sin olvidar aquí que

${ }^{24}$ Cfr MAALOUF, A., Las identidades asesinas, op. cit., pag. 160.

${ }^{25}$ Sobre las incidencias y problemas de este intento, cfr. ECO, Humberto, La busca de la lengua perfecta, Madrid, 1994.

${ }^{26}$ Cfr. SIGUAN, Mikel, España plurilingüe, Madrid, Alianza, 1994. 
una lengua puede ser mayoritaria en un ámbito y minoritaria en otro, por lo que la apelación a los derechos humanos en esta materia no es patrimonio exclusivo de una determinada lengua, sino que puede ser reversible en función de las coordenadas de espacio y tiempo y así, en un medio fuertemente identitario se puede estar marginado si se habla un idioma de amplio poder comunicador, pero se desconoce el idioma de la identidad. También en este supuesto se estará en posición de requerir amparo desde la perspectiva de los derechos humanos ${ }^{27}$.

Desde luego, cuando una palabra o una lengua se muere, fallece con ella toda una concepción del mundo y de la realidad. Por eso las lenguas son patrimonio cultural de la humanidad -su verdadero y prístino patrimonio oral en el sentido que le da la UNESCO- y debe imperar una actitud conservacionista de las mismas, aunque, obviamente, ello no debe impedir la expansión de las grandes lenguas que permitan una comunicación universal, imprescindible en nuestro mundo globalizado.

\section{C) La religión}

Este elemento se basa en la naturaleza religiosa del hombre que es un ser abierto esencialmente a la trascendencia y sensible a los mensajes religiosos por más que existan muchos indiferentes o incluso agnósticos y ateos. Desde esta perspectiva, podría enfocarse la religión como respuesta a un problema puramente individual cual es el anhelo de trascendencia del ser humano. Pero la religión que se profesa es también un componente esencial de la identidad colectiva pues todas las religiones tienen una dimensión social, se proyectan sobre las comunidades y se convierten en fundamentadoras de su identidad y en uno de sus principales referentes. Ahora bien, hay que distinguir a estos efectos entre la religión como dogma, como moral y como rito.

Como dogma, supone el conjunto de verdades de fe que el creyente debe profesar con arreglo a la ortodoxia vigente en la confesión de que se trate. La incidencia del dogma en la identidad deriva, no sólo de la visión de Dios, del mundo y del hombre, es decir, de la visión holística de la realidad que se comparta, sino principalmente de las consecuencias sociales que puede tener la profesión de la fe o, más precisamente, por un lado, el efecto-comunión, esto es, el resultado identitario resultante de la admisión e integración del fiel en la comunidad de los creyentes en la misma fe; y, por otro, el efecto- excomunión en sentido amplio, es decir, el tratamiento y grado o nivel de exclusión social de los infieles o de los fieles que sean reputados por el grupo religioso como herejes, cismáticos o apóstatas.

La religión, por otra parte, en cuanto que moral religiosa, orienta o determina el actuar de los fieles señalándoles una ortopraxis según la doctrina ética vigente en la confesión correspondiente. La incidencia de la moral religiosa en la identidad colectiva deriva, no sólo de su influencia en las costumbres sociales, sino principalmente de las consecuencias derivadas de la mayor o menor flexibilidad que el propio grupo religioso adopte en orden, bien a mantener y promover, o bien a eliminar, las que sean contrarias a los derechos humanos. En este sentido parece claro que, como sostiene José Antonio Marina, el corpus ético que tales derechos representan, se presenta como jerárquica-

\footnotetext{
${ }^{27}$ Para una crítica a la consideración de las lenguas como hechos diferenciales con una propuesta para enfocar el problema desde la perspectiva de los derechos humanos en el marco de un Estado simétrico con homogeneidad competencial, cfr, mis Reflexiones..., op. cit., págs. 128-129.
} 
mente "superior" a las distintas religiones, de suerte que éstas quedan convocadas a revisar aquellos de sus planteamientos o interpretaciones que resulten incompatibles con los derechos humanos, por muy antiguos y respetables que sean tales planteamientos o interpretaciones ${ }^{28}$.

Finalmente, la religión como rito se traduce en una liturgia que requiere unos ministros para administrarla, una jerarquía que los dirija, fije el dogma y señale las orientaciones morales. Requiere, en suma, de una iglesia. Ahora bien, las iglesias, no sólo tienen una importancia sociológica como comunidades de fe que pueden presentarse ante el Estado como sociedades perfectas ${ }^{29}$, sino que también tienen una dimensión identitaria- pues, por su arraigo popular, suelen operar también como elementos de recogida y preservación de cualquier otro componente identitario que resulte perseguido, mientras dure la persecución, y como elementos de proyección reactiva ulterior de la identidad preservada cuando cesa dicha persecución.

Sin duda, la religión puede prestar importantes servicios a la persona humana en sus aspectos individual y social, incluida la dinamización identitaria, pero ha de reconocerse que, precisamente en ésta última faceta, la religión puede derivar también en serias patologías. Así, la religión puede virar hacia la petrificación de la identidad, adoptando posturas intolerantes y reaccionarias que impidan su puesta al día y la posicionen contra los derechos humanos. Por eso, en tales derechos estriba precisamente el quid del equilibrio y, sobre todo, en la dinámica inherente al derecho de libertad religiosa en sus múltiples manifestaciones que obliga a respetar por igual a todas las religiones pero también impone a todas el respeto al corpus ético en que los derechos humanos consisten.

\section{D) El arte, las tradiciones y otros referentes}

También las manifestaciones artísticas ingresan como elementos de la identidad porque se entiende que expresan el espíritu, alma o genio de la comunidad, esto es, el conjunto de valores culturales que la misma estima como sus referentes identitarios.

El término arte engloba aquí todas las manifestaciones artísticas (pintura, escultura, arquitectura, literatura y música) y tanto las realizadas por artistas locales, esto es, pertenecientes a la comunidad identitaria, como las de temática autóctona. Se produce así una doble vinculación a la identidad, por un lado, de tipo subjetivo, por razón de la pertenencia a ella del artista local al que se supone imbuido del espíritu identitario, y, por otro, de tipo objetivo, en cuanto que forma parte de la identidad artística de la comunidad la obra de cualquier autor que, aunque no pertenezca personalmente al grupo, plasme en ella los valores identitarios del mismo.

${ }^{28}$ Cfr. MARINA, J.A, Dictamen sobre Dios, Madrid, Anagrama, 2002, especialmente pags., 172 y s.s.. donde plantea claramente la dialéctica entre la moral religiosa y la ética de los derechos humanos. Cfr. también su Ética para naúfragos, Madrid, Anagrama, 1996.

${ }^{29}$ La idea de sociedad perfecta deriva de la canonística clásica pero fue consolidada por la Escuela del Derecho Público Eclesiástico para dotar de base firme a la acción concordataria de la Iglesia Católica. Este planteamiento sigue siendo básico en las relaciones Iglesia-Estado, si bien actualmente se considera más bien como una consecuencia del derecho humano de libertad religiosa en cuanto que éste exige que las confesiones religiosas y sus plasmaciones institucionales sean autónomas y autosuficientes para el logro de sus fines espirituales en los que resulta por completo incompetente la autoridad política. 
Junto al patrimonio artístico, el histórico y cultural pueden adquirir también una dimensión identitaria. Repárese en que en esta materia operan diversas capas de valoración de los bienes. Por un lado tenemos el mero valor económico del objeto en cuanto que mera res desprovista de cualquier otra consideración, es decir, el valor de uso y de cambio de su continente y, eventualmente, de su contenido. Por otro, el valor artístico, histórico o cultural, que es un valor añadido al anterior merced a la dimensión o relevancia que el objeto en cuestión tiene desde la perspectiva del arte, la historia o la cultura. También puede incidir sobre los anteriores un tercer elemento valorativo que es el plusvalor representado por la relevancia identitaria del bien, esto es, por su incidencia en la identidad de la comunidad correspondiente como signo o símbolo de la misma. Por supuesto, sobre el bien pueden incidir otras varias valoraciones añadidas, como, por ejemplo, el valor religioso.

Estos referentes se incardinan entre los derechos culturales de las colectividades y, por tanto, resulta imprescindible luchar contra la destrucción irreflexiva del patrimonio histórico, artístico y cultural y, mucho más aún, contra su destrucción sistemática y consciente. Aquí se impone una especial sensibilidad para preservar, no sólo el acervo cultural propio sino el de las demás colectividades, lo que explica, por ejemplo, el escándalo producido por la destrucción de las estatuas colosales de Buda en Afganistán. Y es que estas destrucciones conscientes suelen producirse en el seno de movimientos o conflictos inter-identitarios o de afirmación identitaria frente a otras culturas.

La especial consideración identitaria del patrimonio histórico, artístico y cultural no significa que solamente el mismo tenga esa relevancia ya que, en realidad, cualquier cosa o persona que se potencie o cualifique con un nuevo valor añadido consistente en su valoración como símbolo de identidad, le hace ingresar como elemento en el subsistema referencial de la identidad colectiva y, por tanto, en un referente o totem de la tribu identitaria ${ }^{30}$. El caso de los equipos de fútbol es paradigmático en este senti$\mathrm{do}^{31}$.

El acervo cultural engloba, pues, todo tipo de instituciones, costumbres y tradiciones que, en cuanto sean asumidas como propias por la comunidad, se convierten en auténticamente "populares", es decir, ligadas al subsistema referencial. Se comprenden aquí todo tipo de tradiciones, no sólo las etnográficas -como las diversas manifestaciones del folklore popular (trajes, bailes gastronomía)-, sino también las de Derecho consuetudinario y las instituciones administrativas, jurídicas y políticas tenidas como "propias", es decir, en cuanto que valoradas desde la identidad.

${ }^{30}$ Así, por un fenómeno de trasposición, también se incluyen en el subsistema referencial de las comunidades cuantos personajes denoten una biografía meritoria o ilustre desde la perspectiva identitaria de la comunidad correspondiente. Esto explica el interés referencial de las biografías valorativas de personajes ilustres que se consideran prototípicos de la comunidad y sus valores al haber brillado en las artes, la religión, la política o cualquier otro campo vital. En la misma línea se sitúan los honores y distinciones sociales a estos personajes.

${ }^{31}$ La fuerza identitaria explica cómo en muchos países sus éxitos deportivos son celebrados haciendo comulgar entre sí a los distintos símbolos identitarios de la comunidad (celebración en monumentos representativos, ofrecimiento de los trofeos a imágenes veneradas, homenajes desde las sedes centrales de las instituciones populares, etc.). Las pulsiones en esos momentos son tan primitivas que algunos no se contentan con acercarse al monumento emblemático sino que desean encaramarse a él, bañarse en las fuentes que lo adornan, es decir, dejarse penetrar totalmente por la catarsis identitaria, por el pathos que emana de los signos de identidad. 
Sin duda, las tradiciones e instituciones propias tienen gran relevancia en cuanto que integrantes del referente cultural y, en suma, del subsistema referencial de una colectividad, pero también hay que reconocer que una especial insistencia en estos aspectos puede derivar hacia a un autoctonismo mono-cultural esterilizante ${ }^{32}$.

\section{EL CONCEPTO DE IDENTIDAD INDIVIDUAL Y SU DINÁMICA}

Una vez analizada la identidad en sentido colectivo, podemos contemplar la identidad en sentido individual. Desde la perspectiva individual, la identidad se presenta como una pertenencia personal a una comunidad identitaria, de suerte que podemos concebirla como la "creencia, sentimiento y voluntad socialmente reconocido que una persona tiene de pertenecer a una comunidad diacrónica y territorial y participar en el acervo económico y cultural de la misma".

Desde la óptica de aquello a lo que se pertenece o de aquello en lo que se participa, serían aplicables, mutatis mutandis, a la identidad en sentido individual las características que hemos analizado respecto a la colectiva ya que sería la interiorización o asunción individual de aquélla, esto es, la participación de la persona individual en la situación social en que la identidad colectiva consiste que, de este modo, se integra en la esfera individual como una pertenencia.

Así pues, del concepto de identidad en sentido individual que hemos ofrecido resultan como característicos dos aspectos abiertos a una amplia problemática que debemos comentar: las pertenencias y la participación.

\section{LAS PERTENENCIAS: UNIDAD DE IDENTIDAD Y PLURALIDAD DE RE- FERENTES}

La persona humana no opera en la vida social como un ser aséptico desprovisto de cualesquiera raíces sino que, por débiles o remotas que éstas sean, siempre tenderá a reconocer ciertos marcadores o referentes que le vinculan a las coordenadas espaciotemporales en las que se estructuran y en cuyo seno adquieren sentido individual. Tales vínculos son las pertenencias.

Sin embargo, existe un problema que ha planteado muy lúcid amente Amín Malouff y es que, como quiera que la persona humana es esencialmente una, también es una su identidad, es decir, que cada persona sólo tiene una identidad, que es la suya, la cual es indivisible y carece de componentes estancos, por más que sea una identidad compleja, compuesta por muy variados elementos, por muy distintas pertenencias ${ }^{33}$.

Esta idea de la unidad indivisible de la identidad individual, pero una identidad compleja y compuesta, reconduce su análisis al de las distintas pertenencias que la integran y que, para simplificar, podemos conocer a través de los distintos carnés de identidad que nos indican muchas de las "pertenencias" de una persona. En efecto, el ser humano tiene una identidad única pero unas "pertenencias múltiples" y, por eso, la

${ }^{32}$ Así GOMEZ GARCIA, Pedro, en su artículo "Las desilusiones...”, op. cit., pag. 52 se pregunta con gracia qué valor identitario cabe atribuir a dos tradiciones gastronómicas tan etnográficamente acreditadas como la tortilla española o la ensaladilla rusa sin la patata de origen americano.

${ }^{33}$ MAALOUF, A., Las identidades..., op, cit., pág 12. 
pretensión de exclusividad de una de ellas (religión, raza, sexo, etc), rompe la unidad de la estructura óntica de la persona.

Para comenzar, hemos de advertir que existe una relatividad esencial en los elementos identitarios por razón del espacio (por ejemplo, la religión que se profese resulta intrascendente en Estados con verdadera libertad religiosa, pero puede resultar esencial en Estados confesionales; lo mismo que el sexo es indiferente en países desarrollados, pero importante en muchos del Tercer Mundo; o la raza que sigue siendo trascendente en muchos lugares) o por razón del tiempo (no es lo mismo ser mujer o hereje ahora que en el pasado). Por eso no es posible a priori establecer una jerarquización entre las pertenencias para conocer cual es la prioritaria, radical o verdaderamente determinante. Lo que sucede es que la jerarquización se produce de facto cuando una de las pertenencias resulta especialmente apreciada o atacada porque entonces, por razón de la indivisibilidad identitaria que el ser humano tiene por su propia naturaleza antropológica, resulta atacada toda la persona y ésta responde activando más intensamente la pertenencia atacada (por ejemplo, la religión, el sexo, la raza), la cual tiende a absorber a las demás. Es el efecto de desplazamiento de las otras pertenencias por la más atacada, que se convierte así en identidad de resistencia o reactiva. Es el mismo fenómeno que los procesalistas han observado hace tiempo en el mundo de los derechos subjetivos que, por efecto de la lesión de una de sus facultades integrantes, se transforman en acciones, esto es, en derechos en pie de guerra.

De esta suerte, la dinámica de la identidad se traduce en una dinámica de la pertenencia regida por la espiral del agravio-desagravio o de la acción-reacción, dando lugar a dinámicas progresistas o involucionistas en esta materia que, en los casos más graves de estas últimas, pueden degenerar en verdaderos genocidios justificados como una preservación de la identidad. He aquí descrita la génesis individual del conflicto de identidades que está en la base de la famosa predicción prospectiva del choque de civilizaciones ${ }^{34}$.

\section{LA PARTICIPACIÓN: RECONSTRUCCIÓN DE LA PERSONA, ALTERIDAD Y SENTIDO DEL DERECHO.}

La identidad en sentido individual implica, por otra parte, la idea de una participación del sujeto en el conjunto objetivo en que la identidad en sentido colectivo consiste. Se trata de una identificación de los componentes identitarios y una asunción de los mismos para incorporarlos a la propia subjetividad.

Pudiéramos quedarnos en una mera observación superficial de este fenómeno y concluir aquí nuestra reflexión sobre la identidad en sentido individual. Pero, si queremos profundizar en el mismo, se nos hace patente que las opciones personales que implica esta participación nos remiten, en realidad, a dos arduos problemas filosóficos: por un lado, el problema de en qué consiste nuestra propia identidad; y, por otro, el de si esa misma identidad, al ser esencialmente individual, nos permite una verdadera participación en algo distinto a ella misma. Ambos problemas son cruciales porque plantean el concepto mismo de persona humana y sus posibilidades sociales entre las que se encuentra, nada menos, que la fundamentación filosófica del Derecho.

${ }^{34}$ HUNTINGTON, Samuel P. El choque de civilizaciones y la reconfiguración del orden mundial, Paidos, Barcelona, 1997. 
Nos encontramos, pues, ante un asunto central en la historia del pensamiento filosófico ya que, en rigor, trata de responder a preguntas eternas y trascendentales como “)qué somos?, )de dónde venimos?, )a dónde vamos?". Dar respuesta a estas preguntas nos exige analizar nuestro concepto de ser humano, lo que implica una profundización en la estructura ontológica de la persona ${ }^{35}$.

Por mi parte, mantengo una concepción personalista y comunitaria del ser humano. Con arreglo a esta visión, cada uno de los elementos biológicamente individuales que componen el género humano no constituye un sistema unidimensional absolutamente determinado en lo interno por sus pulsiones psicológicas, como quiso cierto psicologismo de origen freudiano, o económicas, como postuló el materialismo dialéctico de raigambre marxista, sino que, lejos de esos modelos estereotipados, se afirma con una dignidad específica que le hace titular de una libertad esencial, así como de derechos inalienables y de responsabilidad que se basan en su propia configuración como ser racional dotado de inteligencia, sentimientos y voluntad suficientes para una propia autodeterminación personal y social y para ser sujeto de su propia esfera de autonomía, por muy condicionada que ésta resulte por causas geno o fenotípicas, como son las psicológicas, las económicas o las culturales ${ }^{36}$.

Esta concepción sitúa a la dignidad humana y a los derechos que le son inherentes en el mismo centro de todas sus reflexiones ya que en tales dimensiones se encuentra toda la fundamentación natural de las instituciones jurídicas, económicas, sociales y políticas.

Pero el problema de la identidad individual es aún más complejo. Como ha observado el filósofo francés Paul Ricoeur ${ }^{37}$, la identidad individual -que Ricoeur denomina ipseidad- no puede afrontarse sin tener presente que uno de sus componentes esenciales es, precisa y paradójicamente, la alteridad. Somos como somos en gran parte merced a lo que recibimos del medio social, de la cultura, de los textos, en suma, de los demás. Esta circunstancia orteguiana -en el sentido literal de aquello que circum-stat al yo individual- es básicamente social y, por tanto, remite necesariamente al "otro", esto es, no sólo , como señala agudamente Remedios Ávila ${ }^{38}$, a "lo Otro" (osea, al mundo de las ideas y los grandes referentes culturales), sino también "al otro", a las otras subjetividades distintas del yo personal pero que también son identificadas como otras tantas personas. Esta distinción -de raíz platónica- entre el mundo de los referentes y el de las personas es clave, pues la moderna pérdida de este universo de referentes, conduce al existencialismo y al nihilismo, en suma, al vaciamiento de la persona que Milan Kundera ha bautizado poéticamente como la insoportable levedad del ser ${ }^{39}$, ese fenómeno que se produce cuando el hombre pierde sus ideales, sus modelos éticos, sus referentes

\footnotetext{
${ }^{35}$ Esta operación resulta imprescindible en Ciencias Sociales ya que las mismas parten de una característica humana como es la sociabilidad, pero las relaciones sociales que la misma comporta, no pueden ser contradictorias con las exigencias ónticas que se derivan de la propia estructura de la persona.

${ }^{36}$ Esta concepción del ser y dignidad de la persona humana es independiente de las ideas religiosas aunque, obviamente, pueden apuntar en la misma dirección, p.e., trascendentalizando el origen y destino sobrenatural de la persona al considerarla criatura divina, objeto de una redención salvífica o llamada a una radical apertura a la trascendencia.

${ }^{37}$ Cfr. RICOEUR, P., Sí mismo como otro, Madrid, Siglo XXI, 1996.

${ }^{38}$ Cfr. AVILA CRESPO, R., "Identidad, alteridad y autenticidad", en Gómez García, P, Las ilusiones de la identidad, op. cit., pags. 205-230.

${ }^{39}$ Cfr. KUNDERA, M., La insoportable levedad del ser, Barcelona, Tusquets, 1986,
} 
${ }^{40}$. y ese vacío existencial tiende a ser rellenado por las identidades colectivas que proporcionan a la persona un señuelo de reconstrucción interior mediante el mecanismo de su participación en ellas. Resulta, así la paradoja de que, en un mundo agobiando por la eclosión de nuevas y viejas identidades colectivas, asistamos a una profunda crisis de identidad individual.

Por eso, si, como enseña Heidegger ${ }^{41}$, se trata de construir una persona que sea un ser-en-el tiempo, esto es, encarnado, insertado y, sobre todo orientado en lo que Forrester denomina el sistema-mundo, es decir, capaz de conocer y dar un sentido al mundo y a su propio proyecto vital en el mismo, sin miedo a la libertad ${ }^{42}$ y con coraje de existir ${ }^{43}$, es forzoso, para reencontrar los referentes perdidos -esa es la gran lección de Proust ${ }^{44}$-, para reinsertarse en las estructuras sistémicas y para, en suma, autoidentificarse, comenzar por descubrir que el mundo constituye, como señalaba Zubiri, una inmensa alteridad, pero en el sentido de que, no es sólo todo lo que no soy yo, sino, prioritariamente, un ámbito habitado por otras personas, por otras alteridades egológicas.

Así, la autenticidad de que hablan los filósofos ${ }^{45}$ se traduce en un verdadero descubrimiento del otro $^{46}$, en un reconocimiento de su identidad y diferencias ${ }^{47}$, en suma, en una apertura trascendental al otro que se consigue reconociendo la alteridad como componente esencial de la propia identidad individual ${ }^{48}$

\footnotetext{
${ }^{40}$ Cfr. BERMAN, M. Todo lo sólido se desvanece en el aire. La experiencia de la modernidad, Madrid, siglo XIX, 1988.

${ }^{41}$ HEIDEGGER, Martín, El ser y el tiempo, Madrid, FCE, 1984; id., Identidad y diferencia, Barcelona, Anthropos, 1988. En rigor, el problema de la identidad es mucho más antiguo pues comienza con el "conócete a ti mismo" de Sócrates y la consideración helenística del hombre como un microcosmos y no puede enfocarse sin analizar el concepto ontológico de identidad en Parménides o en el ego cogitans cartesiano. La consideración filosófica moderna del binomio identidad-alteridad comienza, en realidad, precisamente con la "Quinta meditación cartesiana" de Husserl -cfr. HUSSERL, E., Meditaciones cartesianas, Madrid, Ed. Paulinas, 1979- donde "los otros" son ya reputados fenomenológicamente como objetos y sujetos del mundo, pero el problema no queda centrado hasta la obra de Merleau-Ponty a través de quien lo toma Heidegger y, finalmente, Ricoeur - cfr. RICOEUR, P., "Étude sur les Meditations cartésiennes de Husserl", en Revue Philosophique de Louvaine, 52, 1994, 75-109- y Lévinas. Para un análisis del problema de "el otro" en estos filósofos, cfr. NEBREDA, Jesús José, "El marco de la identidad o las herencias de Parménides”, en Gómez Garcia, P. (coord.), Las ilusiones ..., op. cit., págs. 151-180, especialmente, págs. 162-176; y, más extensamente, con amplias referencias a las aportaciones de Derrida, Deleuze, Foucault y Gadamer, GABILONDO, Ángel, La vuelta del otro. Diferencia, identidad, alteridad, Madrid, Trotta, 2001.

${ }^{42}$ Cfr. FROMM, Erich., El miedo a la libertad, Barcelona, Paidós, 1987

${ }^{43}$ Cfr. TILLICH, Paul, El coraje de existir, Barcelona, Laia, 1973.

${ }^{44}$ Cfr. Proust, En busca del tiempo perdido, Barcelona, Lumen, 2000, trad. Carlos Manzano.

${ }^{45}$ Pese a las críticas de ADORNO, T.W., en La ideología como lenguaje: La jerga de la autenticidad, Madrid, Taurus, 1992, al entusiasmo de Heidegger por este concepto, el mismo ha sido reivindicado por TAYLOR, Ch., en La ética de la autenticidad, Barcelona, Paidos, 1994 y en Las fuentes del yo. La construcción de la identidad moderna, Barcelona, Paidos, 1996.

${ }^{46}$ Cfr. AUGÉ, Marc, El sentido de los otros. Actualidad de la antropología, Barcelona, Paidos, 1996.

${ }^{47}$ El concepto de "diferencia" como componente del binomio identidad-alteridad ha sido especialmente subrayado por la filosofía actual. Cfr. DELEUZE, Gilles, Diferencia y repetición, Júcar, Gijón, 1988; id. La escritura y la diferencia, Anthropos, Barcelona, 1989; id. "La Différance", en Márgenes de la filosofía, Madrid, Cátedra, 1989, pág.. 15-35.

48. En realidad el auténtico y completo proyecto vital no sólo conlleva una referencia y apertura trascendental "al otro", sino también al universo de valores que dan sentido a la vida, es decir, a "lo
} 
Así, como afirma Lévinas ${ }^{49}$, la re-construcción del yo individual ha de comenzar por el re-conocimiento del otro, de la alteridad como uno de sus prioritarios componentes. Repárese en que no decimos -en la línea del pensamiento aristotélico del hombre como animal político o ser social- que la alteridad sea un componente esencial de la identidad colectiva, sino que afirmamos -en línea con el pensamiento agustiniano actualizado en su momento por Ignacio de Loyola y ahora redescubierto por Habermas, Ricoeur y Lévinas- que es componente esencial de la identidad individual ${ }^{50}$.

Por otra parte, la identidad individual conlleva el reconocimiento en uno mismo y en los demás de una continuidad temporal entre pasado-presente y futuro, a la que Koselleck denomina espacio de experiencia y horizonte de espera ${ }^{51}$. Se trata de una continuidad de memoria que permite, "ad intra" afirmar el propio yo -es lo que Ricoeur denomina atestación de la ipseidad- y, "ad extra" asumir lo que Gadamer ${ }^{52}$ denomina las tradiciones, es decir, entrar en diálogo constructivo con todo el acervo cultural del mundo, o sea, con la alteridad que representan los otros. De esta forma, la moderna filosofía personalista del otro sienta las bases de la posibilidad del diálogo cultural y, en suma, de la convivencia social. Quedan así sentadas también las bases del Derecho, ya que, como apunta Ricoeur, la esencia de la personalidad estriba en la fidelidad a la palabra dada, esto es, en la autorresponsabilidad frente a otros inherente al concepto de fides que resulta esencial para toda construcción jurídica ${ }^{53}$.

Este reconocimiento fundamenta en la propia dignidad humana la base dialogal con toda otra identidad y convierte el diálogo de identidades en una exigencia óntica de la propia persona. Y, como quiera que la alteridad es presupuesto necesario de la justicia, queda patente que la dimensión de justicia es una de las inherentes al estructo óntico de la persona humana. He aquí el fundamento profundo del Derecho y, sobre todo, del Derecho Público, de toda norma jurídica que instrumente un diálogo intercultural entre colectividades y seres humanos.

Ahora se comprende por qué Habermas pre-titula sus Estudios de Teoría Política como "la inclusión del otro" ya que la democracia, como realización humana, ha de ser coherente con la estructura óntica de la persona, y, por tanto, tiene una lógica naturalmente inclusiva de la alteridad .

La identidad cuenta, pues, con un estatuto propio en la Teoría Política. Existe una dimensión política y jurídica de la justicia. En efecto, el excursus que hemos realizado por el panorama filosófico actual revela que el Derecho no es una mera superestructura artificialmente añadida a las relaciones sociales para dotar a los intereses económicos subyacentes en la estructura social de una protección especialmente intensa,

Otro", como acertadamente concluye. ÁVILA, Remedios., "Identidad, alteridad y autenticidad”, en Gómez García, P., Las ilusiones..., op. cit, pág. 230.

${ }^{49}$ Cfr. LÉVINAS, E, Totalidad e infinito. Ensayo sobre la exterioridad, Salamanca, Sígueme, 1995; Humanismo del Otro hombre, Madrid, Caparros, 1993; y Fuera del sujeto, Madrid, Caparros, 1987.

${ }^{50}$ Aquí está el engarce con el amor que recalca FROMM, Eric, en El arte de amar, que ha tenido múltiples ediciones, p.e. la de Paidos, Barcelona, 1998 y que LEGAZ LACAMBA tradujo al mundo jurídico en su obra El derecho y el amor, Boch, Barcelona, 1976.

${ }^{51}$ KOSELLECK, R., Futuro pasado. Para una semántica de los tiempos históricos, Barcelona, Paidos, 1993.

${ }^{52}$ Cfr. GADAMER, H., G., Verdad y método, Salamanca, Sígueme, 1977.

${ }^{53}$ RICOEUR, Sí mismo como otro, op. cit., pag. 149. Este concepto ha sido desarrollado por DERRIDA, Jacques, en Fuerza de ley. El fundamento místico de la autoridad, Madrid, Tecnos, 1997. 
sino que encierra un fenómeno mucho más rico y profundo. En rigor, se trata de que la justicia constituye una dimensión de la alteridad anclada firmemente en la estructura óntica del yo-mismo, en la propia identidad personal de la que arranca esa fides trascendental (fidelidad a la palabra dada y, en suma, auto-responsabilidad) que está en la base de todo fenómeno jurídico.

Este anclaje personalista y antropológico del Derecho o, si se prefiere, este redescubrimiento de la esencia y sentido del Derecho en el marco de la re-construcción moderna de la persona humana y de sus relaciones sociales o de alteridad, es el que nos permite aventurar la existencia de posibles soluciones jurídicas para los actuales problemas derivados de las crisis y conflictos identitarios e interidentitarios. Tal será el objeto del siguiente epígrafe con el que concluiremos el presente estudio.

\section{IDENTIDAD Y DEMOCRACIA: ALGUNAS SOLUCIONES.}

En los epígrafes anteriores he tratado de presentar el panorama que presenta modernamente la identidad, un panorama no diría que grave -ya que encierra aspectos francamente esperanzadores-, pero sí muy delicado, inestable y abierto a atrocidades ejecutadas en nombre de los más elevados principios. Por eso la identidad supone un reto para la democracia. Pero entiendo que la solución no esta en prescindir de la identidad sino en integrarla armónicamente en el sistema.

En efecto, los procesos de identificación se han abierto por doquier para ofrecer al hombre actual, esa persona desestructurada y desorientada, los referentes y el arraigo que la sociedad globalizada le hurta día a día. Este fenómeno puede considerarse positivo en sí mismo ya que el hombre es un ser-en-él-mundo y el sistema-mundo aparece organizado en sub-sistemas identitarios que ofrecen al hombre el apoyo dialogal y referencial que requiere su propia ontología ansiosa de sentido en lo inmanente y en lo trascendente. Así pues, las identidades juegan un papel importante en la reconstrucción de la persona humana que obliga a considerarlas como un fenómeno positivo de socialización, de personalización constructiva, de humanización, en suma, del planeta. Me parece, pues, claro que las identidades colectivas ayudan a arraigar a la persona en el medio objetivo social, implementan su proceso de socialización y, en última instancia, la humanizan y personalizan puesto que coadyuvan a reconstruir la esencia de la persona que parecía diluida, destruida o, al menos, en la terminología de Gadamer, deconstruida ${ }^{54}$, merced al determinismo existencial. psicológico o económico preconizado por el pensamiento existencialista, nihilista, psico-analítico post-freudiano o marxista que imperó en la cultura occidental en la segunda mitad del siglo XX.

Ahora bien, junto a ese efecto francamente positivo, es igualmente claro que las identidades pueden incidir negativamente en la persona humana y en sus comunidades si alientan la crisis de identidad individual, exacerban las pertenencias más agraviadas, las extrapolan hasta el punto de inundar la identidad individual y lanzarla junto con otras a un conflicto de identidades cada vez más amplio e intenso donde la intolerancia

${ }^{54}$ Cfr. GADAMER, Hans-Georg, "Destrucción y Deconstrucción”, en Verdad y Método, II, Salamanca, Sígueme, 1993, págs. 349-359. Sobre este asunto, cfr..Gómez Ramos, A. (ed.), Diálogo y deconstrucción. Los límites del encuentro entre Gadamer y Derrida, Madrid, Cuaderno Gris-Universidad Autónoma de Madrid, ep. III, núm 3, 1998, págs. 65-74. 
suplante al diálogo y la exclusión a la inclusión del otro, generando así una galaxia de mónadas identitarias cerradas y mutuamente recelosas o abiertamente enfrentadas.

Se impone, pues, que los juristas, a quienes se nos supone institucionalmente llamados a profundizar en las consecuencias sociales de la dimensión de justicia que implica la inserción de la alteridad en la estructura óntica del ser humano, así como a prevenir los enfrentamientos, procurar la solución pacífica de los conflictos sociales y pacificar los ámbitos donde el enfrentamiento y la confrontación ya se hayan producido, no nos limitemos a conocer y analizar el problema de los efectos negativos de las identidades, sino que, dando un paso más, reflexionemos sobre algunas posibles soluciones. Esto resulta especialmente necesario en nuestros días, es decir, ahora precisamente cuando sabemos que filosóficamente el Derecho cuenta con un basamento seguro en la antropología de la alteridad y que, por tanto, se ubica rigurosamente en línea con toda la problemática que la identidad comporta.

Por de pronto, parece prudente afirmar que, ante posibles conflictos entre identidades, es preciso adoptar una actitud preventiva. Ahora bien, para prevenir hay que conocer el problema, analizar sus causas (esto es, fijar la etiología del conflicto), determinar cuál es su situación actual (o sea, describir la anatomía del conflicto) y cuáles sus peligros de futuro (lo que significa penetrar en la patología del conflicto), con objeto de arbitrar soluciones que puedan, primero, detectarlo, aislarlo, paliarlo y, luego, resolverlo.

Este empeño -que recuerda mucho a las funciones de peace making asignadas a los ejércitos en la moderna doctrina estratégica- resulta imprescindible si nos situamos en la órbita y perspectiva del Derecho Comparado. En efecto, es obvio que la doble dinámica de la globalización -caminamos hacia un mundo cada vez más mundialmente inter relacionado en cuanto a flujos económicos y redes comunicacionales- y la identificación -al mismo tiempo surgen y se afirman las identidades colectivas más variopintas-, sitúa a los distintos sistemas jurídicos nacionales -y, en los Estados compuestos, también los subsistemas jurídicos de los "fragmentos de Estado" sean Regiones, Comunidades Autónomas o Estados federados que los integran- ante un doble y aparentemente contradictorio movimiento. Por un lado, se ven abocados a una imparable armonización para converger con otros sistemas en ordenamientos comunes cada vez más complejos y completos; por otro, experimentan la necesidad de preservar los valores de la propia cultura jurídica, de potenciar sus instituciones peculiares y afirmar sus singularidades identitarias, en un proceso que podemos denominar de afirmación e identificación. Conjugar ambos movimientos para lograr los efectos positivos que encierran, eliminando o minimizando los negativos, constituye el principal reto jurídico de nuestra generación. Desde esta perspectiva, el amplio debate suscitado en el seno de la Unión Europea sobre la virtualidad y funciones del principio de subsidiariedad no es sino un episodio reflejo de esta doble dinámica a la vez centrífuga y centrípeta a la que nos referimos.

Pues bien, a mi entender, una vía de solución jurídica a este grave problema se encuentra en la idea de institucionalización de los círculos concéntricos de competencias identitarias sobre la base de una centralidad radical de la dignidad de la persona y de los derechos humanos. 
Analicemos los dos elementos de esta proposición: la institucionalización de los círculos concéntricos de competencias identitarias y la centralidad radical de la dignidad de la persona y de los derechos humanos.

\section{LA INSTITUCIONALIZACIÓN DE LOS CÍRCULOS CONCÉNTRICOS DE COMPETENCIAS IDENTITARIAS}

El problema de las identidades colectivas desde el punto de vista politológico es que ha sido monopolizado por los nacionalismos y, además, distorsionado por los excesos nacionalistas radicales, lo que ha generado una prácticamente unánime corriente doctrinal en el sentido de abominar de la idea de identidad para centrarse únicamente en el clásico irenismo de los derechos humanos universales. Huyendo, así, de un mal se ha incurrido en otro, ya que, a mi entender y en coherencia con lo que vengo sosteniendo en este trabajo, tan injusto es incurrir en un reduccionismo nacionalista sólo atento a las propias identidades nacionales, como incurrir en un reduccionismo universalista sólo atento a los elementos comunes a toda la humanidad con olvido de los factores identitarios nacionales o de menor ámbito.

Para evitar ambos extremos que privan a la persona humana de sus dimensiones identitarias universales y particulares, hace tiempo que formulé la que denomino teoría de los círculos concéntricos.

\section{A) La teoría de los círculos concéntricos}

Esta teoría parte de la idea de que existen diversos ámbitos de identidad. Existe, por supuesto, el ámbito de identidad nacional que es el prioritariamente descubierto en el siglo XIX por el denominado principio de las nacionalidades, con arreglo al cual toda identidad colectiva tenderá a institucionalizarse estatalmente.

Junto a esa identidad nacional que condujo a la creación de los grandes Estadosnación, existe también una identidad regional o "nacional" - no institucionalizada como Estado pero que puede estar perfectamente reconocida por las Constituciones estatales-, que puede convivir con otras en el seno de un mismo Estado plurinacional o incluso abarcando diversos Estados.

Esta evidencia no significa tanto la crisis del Estado-nacional clásico - surgido en el siglo XVI, potenciado tras la revolución política del s. XVIII e impulsado por los movimientos de re-unificación nacional del siglo XIX-, cuanto la no menos evidente emergencia de identidades colectivas de cuño nacional pero no necesariamente estatales. Ese reconocimiento hace que los modernos Estados se conciban como plurinacionales y se institucionalicen adoptando formas compuestas de distribución territorial del poder con arreglo a modelos regionalizados o federales ${ }^{55}$.

${ }^{55}$ Entre nosotros, el reconocimiento por el Prof. González Navarro, de España como una Nación de Naciones a la luz del artículo 2 de nuestra Constitución (GONZÁLEZ NAVARRO, Francisco, España, Nación de Naciones, el moderno federalismo, Pamplona, EUNSA, 1993), levantó una polvareda entre los defensores a ultranza de un nacionalismo estatal unitario y los partidarios de interpretar nuestra forma de Estado en clave federal. Personalmente me siento poco inclinado por dicha polémica ya que entiendo que lo relevante no es la calificación que nuestra forma de distribución territorial del poder merezca a la luz de la tipología de formas de Estado que ofrece la dogmática al uso, sino la profundización en los mecanismos y técnicas de coordinación, cooperación y solución de conflictos. Muchas de esas técnicas son bien conocidas en Derecho Constitucional Comparado y tienen indudable raíz federal. Sin embargo, hay 
En este sentido, el avance en las técnicas federales constituye el más serio intento de armonizar la necesaria convivencia del viejo Estado nacional con los emergentes poderes regionales y locales. Y digo necesaria porque me parece obvio que la convivencia social no puede ya construirse sobre la base de negar las identidades infraestatales ni de reconducirlas todas al modelo clásico de Estado, como tampoco de negar a éste toda virtualidad. Por el contrario, estimo, en definitiva, que es preciso afirmar la existencia de, por de pronto, dos grandes círculos identitarios: el estatal, que asume todos los referentes de ese ámbito, y el que podemos denominar regional, que está llamado a institucionalizar los del suyo ${ }^{56}$.

Pero tampoco podemos incurrir en un reduccionismo que limite las identidades a las estatales y regionales, ya que es obvio que el ser humano experimenta pertenencias de ámbito universal e individual, pasando por las de ámbito internacional, local o doméstico y familiar. La casa común en que nuestro mundo consiste es para todos y encierra muy diversas estancias de suerte que no es contradictoria la pretensión de pertenecer, simultáneamente o sucesivamente, a varias de ellas.

En efecto, existen pulsiones y referentes que nos remiten a cuanto de común tenemos con nuestros congéneres del pilum evolutivo de los homínidos que ha conducido al actual Homo Sapiens, lo mismo que resulta innegable la existencia de problemas de ámbito internacional o incluso mundial que requieren igualmente soluciones del mismo nivel. Junto a esta constatación, es claro que existen también referentes y pulsiones de ámbito estrictamente individual, lo mismo que hay problemas que se plantean y deben solventarse en el nivel doméstico-familiar o municipal. El ejemplo del medio ambiente resulta elocuente en este sentido ${ }^{57}$. Este ejemplo puede ser acompañado de muchos

dos ideas que me parecen claves para el adecuado funcionamiento de nuestra peculiar forma de Estado compuesto que es el denominado Estado de las Autonomías: la simetría del modelo y la homogeneidad competencial. He profundizado ampliamente en ambas cuestiones en Reflexiones..., op. cit., págs. 117136. En el fondo, estimo que esta polémica está trascendida por una incomprensión de la funcionalidad que encierran los tres grandes sentidos que la doctrina germánica ha descubierto después de Kelsen en el polisémico término castellano de Estado: Estado-global (Gesamstaat) que integra todo tipo de poderes públicos, incluídos aquí los autonómicos; Estado central (Oberstaat) como instancia opuesta a los poderes públicos autonómicos; y "Fragmentos de Estado" (Gliedstaat) que precisamente se refiere a esos poderes públicos autonómicos. Cfr. JELLINEK, G., Fragmentos de Estado, Madrid, Civitas, 1981.

${ }^{56}$ Empleo aquí el término "regional" en aras de la brevedad y sin ningún sentido peyorativo o de minusvaloración, sino más bien tratando de englobar en el mismo esos que Jellinek denominó "fragmentos de Estado" y que tanto comprenden los Estados federados como nuestras Comunidades Autónomas, los Länder alemanes o las Regiones italianas, por ejemplo.

${ }^{57}$ Fumar en exceso constituye un problema básicamente de ámbito personal que requiere un tratamiento a este mismo nivel, sea de concienciación o quizá médico. Si se fuma en un ambiente en que están otras personas a las que desagrada el humo, el problema adquiere otra dimensión y la solución vendrá por una ordenación colectiva, normalmente a través de informales usos sociales de educación y convivencia, aunque no cabe excluir la presencia de una reglamentación más detallada que asegure el derecho a respirar un aire no contaminado, pero todavía es un problema de ámbito acusadamente doméstico por lo reducido del círculo de posibles afectados. Hay, sin embargo, emisiones de humo más intensas que pueden generar ya un problema de ámbito local que deba resolverse precisamente en el nivel municipal, como sucede con las emanaciones procedentes de una pequeña o mediana fábrica industrial. No hace falta ser muy perspicaz para apreciar que existen niveles potencialmente contaminantes que requieren normación y tratamiento de ámbito regional o incluso estatal como sucede con las grandes instalaciones fabriles, complejos petroquímicos o centrales nucleares. Pero es que, si la emisión contaminante es del calibre que se produjo al estallar la Central ucraniana de Chernobil, nos encontramos ya ante un problema de dimensiones internacionales, lo mismo que el efecto que en la capa de ozono pueden producir el conjunto 
otros y revela que no puede negarse la existencia de diversos círculos o ámbitos de problemas: el individual, el doméstico, el local, el regional, el estatal, el internacional, el mundial. Pero en el bien entendido de que no se trata de afirmar que existen problemas en todos esos niveles, sino de tomar conciencia de que cualquier problema puede derivar hacia esos niveles según sus variables cuantitativas o cualitativas.

Aceptar este planteamiento es crucial en orden a la regulación de la distribución territorial del poder y, más técnicamente, al reparto de competencias jurídico-públicas. Se trata de un problema sólo aparentemente técnico ya que, en el fondo, implica una profunda reflexión sobre una cuestión crucial como es la de quién puede hacer qué; una cuestión en la que las comunidades y grupos humanos nos jugamos nada menos que la libertad.

En efecto, hace tiempo que la libertad no tiene sólo un sentido de liberación personal de los grilletes de la esclavitud y que no se ciñe exclusivamente a la libertad personal de que hablan nuestras Constituciones frente a detenciones arbitrarias o para permitir un libre flujo o circulación de personas y cosas por un ámbito espacial concreto. Esos sentidos podemos decir clásicos de la libertad siguen siendo esenciales y nunca deben olvidarse, sobre todo en los países que se incorporan al desarrollo económico y a la democracia. Pero la libertad que ahora interesa más en las democracias desarrolladas es la libertad de los grupos en los que el individuo se integra. Esa es la libertad que las comunidades identitarias han de reivindicar para auto-organizarse, para institucionalizarse, para actuar en la vida social y para que sus componentes ejerzan en pie de igualdad los derechos humanos.

Ahora bien, esta libertad grupal o colectiva está íntimamente ligada a otro valor fundamental también erigido en derecho humano cual es el de igualdad que, desde luego, tiene una vertiente individual - la que trasluce en las comparaciones que, en el seno de un mismo sistema jurídico, pueden darse entre situaciones jurídicas individuales que objetivamente debían ser iguales en cuanto a su tratamiento en Derecho y que, sin embargo, son tratadas jurídicamente como desiguales sin una justificación objetiva para ello-, pero también encierra una dimensión o vertiente colectiva, ya que me parece evidente que la legítima diferencia que comporta el necesario reconocimiento de las distintas identidades colectivas implica el también el necesario tratamiento jurídico igualitario de todas ellas y, por tanto, proscribe los tratamientos jurídicos desiguales. Me parece, pues, axiomático que diferencia no significa desigualdad ${ }^{58}$.

Me posiciono así en contra de los denominados "hechos diferenciales". El adjetivo diferencial, al contrario que el adjetivo diferente, implica, no una evidente y legítima constatación de las diferencias que están en la base misma del, para mí, imprescindible -incluso desde una perspectiva filosófica y antropológica- reconocimiento de la diversidad de identidades colectivas, sino una inaceptable apelación a un, desde mi punto de vista, injustificable derecho a un tratamiento jurídico desigualador. Entiendo que éste último resulta inexistente y no puede reconocerse desde la perspectiva de la

de emisiones del mundo ,supone plantear un problema que requiere soluciones a escala mundial o planetaria.

${ }^{58}$ Lo ha expresado perfectamente PÉREZ TAPIAS, José A., “)Identidades sin fronteras?...”, op cit., pag. 68, cuando afirma, por un lado, que hay que aplicar rigurosos "criterios normativos para una sana reconstrucción de las identidades, tomando en serio a la vez las diferencias y el principio de igualdad desde el que aquellas pueden salvarse sin discriminaciones"; $\mathrm{y}$, por otro, que esto debe hacerse "desde y a través de las diferencias que, en ningún caso, hay que confundir con las desigualdades" 
dogmática, tanto de los derechos humanos como de los derechos constitucionales fundamentales ${ }^{59}$.

Esto dicho, parece claro que actualmente ya no es posible reivindicar una soberanía estatal plena a la antigua usanza debido a que la teoría de los círculos concéntricos impone - y lo hace desde la dogmática de los derechos humanos- distintos ámbitos competenciales (personal, social, local, regional, estatal, continental, mundial), ninguno de los cuales puede prescindir de los demás.

Pues bien, si esto es así, no cabe duda de que los excesos e incluso crímenes abominables que se han cometido en nombre de las identidades no pueden hacernos olvidar que la estructura óntica profunda de la persona exige, como una dimensión inherente a la dignidad esencial de la misma, reconocer, proteger y defender todas las identidades, incluidas, por supuesto, las colectivas, y, para ello, nada mejor que recurrir la técnica de la institucionalización de cada uno de sus elementos (lengua, religión, etc.) y de la identidad sistémica resultante de su integración.

\section{B) La técnica de la institucionalización de las identidades}

Una institución es una estructura permanente y duradera, por tanto, transpersonal que consta de un fin fundacional propio, unos medios adscritos a conseguirlo y una organización destinada a gestionarlo, realizando aquellos fines mediante la aplicación a los mismos de los medios correspondientes.

Hay instituciones de muy distinto tipo (sociales, culturales, políticas, religiosas) pero todas ellas son necesarias para vertebrar la sociedad, reconocer las distintas pertenencias de las personas, preservar y, eventualmente, defender los elementos identitarios de las diversas comunidades sociales. Observese que empleo deliberadamente la expresión comunidades sociales pues, aunque comunidad y sociedad son tipos asociativos distintos, me refiero a una sociedad donde conviven ordenadamente diversas comunidades identitarias. El sintagma clave es "ordenadamente" porque remite a una consideración jurídica. En efecto, es en el Derecho y por el Derecho como las relaciones de pertenencia propias de las asociaciones comunitarias, logran conformar con las demás una ordenada convivencia y articularse en una asociación de tipo societario común.

Concibo, pues, una sociedad de comunidades institucionalizadas cuya convivencia pacífica está ordenada por el Derecho en los distintos círculos concéntricos en que distribuye el poder humano y, singularmente, en el circulo estatal.

Como puede colegirse, esta concepción implica engarzar el sistema identitario con el sistema jurídico, es decir, hacer penetrar la estructura jurídica de la sociedad en el sistema en que cada identidad consiste, de suerte que el sistema identitario quede juridificado, lo mismo que el Derecho queda trascendido de sensibilidad identitaria. Se trata, pues, de una verdadera sistemización ${ }^{60}$ sobre la base de incardinarlo ordenadamente

${ }^{59}$ Cfr. el epígrafe "Hechos diferentes pero no hechos diferenciales" de mis Reflexiones..., op. cit., págs. 128-133.

${ }^{60}$ Sistemización, no sistematización, ya que no consiste en un esfuerzo meramente teórico por explicar sistemáticamente el problema identitario analizando ordenadamente sus distintos elementos, sino en una labor eminentemente práctica que supone comprenderlo, integrarlo, superarlo y, por tanto, resolverlo, 
en un sistema superior cual es la sociedad jurídicamente regulada, pero una sociedad de comunidades identitarias.

Este engarce de la identidad con el Derecho es transversal e implica todas las ramas del ordenamiento jurídico por lo mismo que es susceptible de afectar a múltiples instituciones jurídicas tanto públicas como privadas o mixtas, desde las comerciales, a las familiares, desde las tributarias a las administrativas. Ello es así porque la institucionalización a que me refiero no afecta únicamente al ámbito de relaciones estatales, sino también al ámbito de relaciones meramente sociales. En otras palabras, no estoy diciendo que haya que crear instituciones meramente jurídico-públicas que sean susceptibles de actuar en al campo de los poderes públicos, sino también instituciones privadas capaces de penetrar en la red compleja de relaciones en que una sociedad civilizada consiste. Por eso utilicé antes con toda intención el término orteguiano "vertebrar".

En efecto, para mí, vertebrar una sociedad es concebirla organizada horizontalmente en círculos concéntricos de identidades institucionalizadas, pero también trascendida verticalmente por instituciones sociales expresivas de las más diversas pertenencias de que es susceptible la persona. Este entrecruce de círculos y radios identitarios institucionalizados, sectoriza la sociedad en innumerables segmentos expresivos de otros tantos matices pertenenciales, todos los cuales se autoidentifican en su círculo e institución correspondiente y, simultáneamente, en el sistema-mundo que los engloba a todos. Esta sociedad, multicultural, pluralista, enormemente compleja está, sin embargo, vertebrada merced a la institucionalización de las distintas identidades que la integran en círculos sistémicos sucesivos y se acerca así al modelo, unitario pero complejo y compuesto, de la propia estructura antropológica de la persona humana individual que, en definitiva, la construye ${ }^{61}$.

Es claro, pues, que el engarce institucional, sistémico e inter-identitario en que esta vertebración social consiste, afecta prioritariamente a las tres grandes ramas fundantes del fenómeno jurídico: la Filosofía y Sociología del Derecho, la Historia del Derecho y, de forma muy especial, al Derecho Constitucional, pero, fiel a mi concepción unitaria y sistémica -aunque pluridimensional- del fenómeno jurídico, prefiero seguir razonando desde una perspectiva global del mismo, puesto que entiendo que la lógica holística es la única capaz de tratar adecuadamente el intrincado y antigüo problema filosófico de las relaciones entre el todo y las partes..

En este sentido, las instituciones propias de cada una de las comunidades identitarias generan una dinámica ad intra tendente a la afirmación, preservación y conservación de los elementos de su propia identidad, pero también producen una dinámica $a d$ extra tendente a su reconocimiento, protección y defensa por la sociedad (es decir, en el seno del círculo superior en que la sociedad consiste y en el marco de las relaciones con otras comunidades identitarias). El Derecho debe asegurar que ambos diálogos, el intrasistémico y el intersistémico, se desarrollen ordenadamente y con respeto a los derechos humanos y eso sitúa el problema del engarce de las identidades con el Derecho precisamente en la óptica del Derecho Constitucional.

${ }^{61}$ Así, si evolutivamente la ontogénesis reproduce la filogénesis, filosóficamente también existe una correspondencia entre el cosmos y el microcosmos en el hombre consiste. Esta vieja idea de la filosofía helenística influyó notablemente en la cosmovisión democrática de Teilhard de Chardin, un aspecto muy poco estudiado de su pensamiento .Cfr. TEILHARD DE CHARDIN, Pierre, Esbozo de un universio personal, estudio, notas y comentarios por Jose Maria Fornell, Madrid, Narcea, 1975. 
En efecto, desde el punto de vista constitucional, las instituciones de las comunidades identitarias deben gozar de autonomía constitucionalmente garantizada y para ello no disponemos todavía de una técnica más depurada que la de la garantía institucional que permite asegurar a las comunidades identitarias sus elementos de identidad, sus signos distintivos propios y su propia dinámica organizativa.

Como es sabido, la garantía institucional trata de permitir una preservación de la imagen que tradicionalmente identifica a la comunidad identitaria correspondiente, asegurando a la misma un ámbito de autonomía -en el sentido de auto-organización, autogobierno y auto-normación- suficiente para conservarlo y desarrollarlo, pero siempre dentro de los límites que impone el respeto a los iguales derechos que deben reconocerse a las demás comunidades identitarias del nivel correspondiente.

El ámbito propio de autonomía institucionalmente garantizada debe ser siempre definido por normas incardinadas en un círculo normativo superior a aquel en que opera la institución cuya autonomía se trata de garantizar ${ }^{62}$. Esto explica que normalmente sean las Constituciones las que garanticen dicho ámbito, si bien el texto constitucional puede limitarse a fijar un núcleo duro como contenido esencial del derecho a la autonomía de la institución de que se trate, de suerte que penetrar en el mismo resulte vedado para el legislador ordinario o bien construir una autonomía de las denominadas de configuración legal, donde dicho legislador resulte habilitado más o menos ampliamente para regular aspectos de la institución correspondiente ${ }^{63}$.

El modelo de institucionalización por círculos concéntricos es, pues, sensible a las diferencias entre referentes identitarios y admite, por lo tanto, una gran flexibilidad institucionalizadora de identidades -especialmente en el marco meramente social más que en el de los poderes públicos-, pero dicho modelo debe ser rígido en cuando a discriminaciones injustificadas entre instituciones identitarias, como antes hemos señalado.

En suma, el modelo que preconizo conduce a una actitud constitucional proteccionista muy similar a la que se adopta en materia medioambiental para proteger la biodiversidad y las especies amenazadas, no sea que terminemos protegiendo más algunos tipos de animales y plantas que nuestra propia diversidad cultural. Por eso A. Malouff ha propuesto con razón conjugar las exigencias de la economía, que tiende a la universalización, la armonización de sistemas y la comunicación global, con las de la ecología que tiende a la protección y la conservación de la diversidad, identitaria y cultural, en este caso ${ }^{64}$.

${ }^{62}$ Va ínsita en la lógica de la institucionalización identitaria por círculos concéntricos la necesidad de que, desde el círculo superior correspondiente que podemos denominar círculo de encuadramiento, se definan los parámetros precisos para integrar las distintas piezas en el sistema conjunto.

${ }^{63}$ Puede servirnos como paradigma a estos efectos la doctrina fijada por el Tribunal Constitucional español aplicando la técnica de la garantía institucional con respecto a la autonomía local ( SS 4 y 32/1981, 38/1983, 27/1987, 109, 213 y 259/1988 y 214/1989, entre otras), a los derechos históricos de los territorios forales que, reconocidos por la Disposición Adicional Primera de la Constitución española vigente, subsisten en el País Vasco y Navarra (SS 159/93, 123/1984, 76/1988 y 159/1993) y a la autonomía universitaria (SS 26/1987, 106/1990, 187/1991, 156/1994, 179/1996 75 y 155/1997 y 103/2001).

${ }^{64}$ Creo que eso es lo que pretende también decir BALLESTEROS, Jesús, en su obra Ecologismo personalista, Madrid, Tecnos, 1995. 


\section{LA CENTRALIDAD RADICAL DE LA DIGNIDAD Y LOS DERECHOS HUMANOS}

El programa de soluciones que nos hemos propuesto requiere, además de la institucionalización identitaria por círculos concéntricos, una actitud de centralidad radical de la dignidad y los derechos humanos.

Hemos indicado cómo en nuestros días nos encontramos ante dos movimientos aparentemente contradictorios: Por un lado, la mundialización o globalización que nos exige integrarnos cada vez más intensamente en un mundo y una sociedad cuya red de interrelaciones, facilita por los flujos económicos y los nuevos medios de comunicación, abarca todo el planeta convertido en un verdadero sistema-mundo; y, por otro, la identidad colectiva e individual que resulta una exigencia óntica de la propia estructura de la persona humana que está trascendida por sus circunstancias genotípicas (como el sexo o la raza) y fenotípicas (como la cultura, la lengua, la religión y demás elementos identitarios) que, si no la determinan de forma absoluta, desde luego la condicionan y modulan poderosamente.

Ambos movimientos propios de la vida moderna operan como catalizadores de dos impulsos diferentes de la persona humana: el trascendental que la proyecta hacia el horizonte de una cada vez mayor convergencia universal, y el identitario que la impele a encontrar sus propias raíces y profundizar más personalmente en el propio medio subjetivo y objetivo.

Globalización e identidad se sitúan así en los extremos de una dialéctica que, si no queremos que sea mortífera, ha de conducir a una síntesis armonizadora y ese ámbito sintético de pacificación y convivencia civilizada es precisamente el que más ha de apasionar a un jurista.

Recuerda A. Maalouf ${ }^{65}$ cómo según el conocido historiador británico Arnold J. Toynbee (1973), la evolución humana atraviesa tres grandes fases: una primera, que corresponde con la Prehistoria, en que el conocimiento y la comunicación son pocos y lentos, por lo que el desarrollo humano es prácticamente igual en todas las comunidades; una segunda, que corresponde con las Edades Media y Moderna, en que el conocimiento aumenta rápidamente, pero no tanto su comunicación, por lo que surgen grandes diferencias entre unas y otras comunidades; y una tercera fase, que es la actual, en que el conocimiento y la comunicación son muy rápidos, por lo que se tiende a una nueva igualación universal. Pues bien, el problema que la globalización comporta para las identidades es que no se construya con los signos y elementos de la propia identidad (lengua, cultura y religión), sino con los de "otras" identidades, por lo que puede generar un doble movimiento, simultáneo pero contradictorio, de aproximación y, a la vez, de rechazo, lo que introduce factores de armonización pero también de resistencia.

La única salida razonable a esta dinámica es considerar, nuevamente en palabras de Amín Malouff, que el mundo es de todos, por lo que también deben serlo aquellas partes del mismo que hemos dado en denominar "sociedad del conocimiento" y "de la comunicación". Debemos participar en el sistema-mundo globalizado, como sugiere el citado escritor libanés, para que sea también, un poco nuestro y no nos sintamos extraños y ajenos al mismo, sino como algo que es, en parte, propio. Estamos, pues, abocados a una colonización multi-identitaria del mundo con objeto de no establecer con el mismo relaciones de alienidad sino de integración, de suerte que la dimensión global

${ }^{65}$ MAALOUF,A., Identidades asesinas, op. cit., pág. 110. 
se convierta también en una de las pertenencias de nuestra propia identidad, en uno de los círculos -el más amplio y extenso- en que ordenar nuestra identidad.

Ahora bien, esto exige medidas político-jurídicas que lo posibiliten. Para comenzar, es preciso partir de una proclamación y reconocimiento sin paliativos de la dignidad humana que ha de ocupar el centro mismo del sistema jurídico y político. La identidad individual es respetable porque se fundamenta en la estructura antropológica misma de la persona, en esta apertura trascendental al otro, en esta dimensión a la vez de ipseidad y alteridad de que nos hablan la moderna filosofía. Cualquier planteamiento ideológico que no parta de este reconocimiento radical debe ser rechazado.

La dignidad humana es, por tanto, en la terminología de Khun ${ }^{66}$, el paradigma en torno al cual se estructura cualquier modelo o sistema de institucionalización social, también los de carácter identitario.y ese paradigma el que ha de impedir cualquier tendencia a un conflicto de identidades y, por supuesto, al indeseable choque de civilizaciones. Por mi parte, más que en el apocalíptico panorama diseñado por Huntington ${ }^{67}$, prefiero dejarme seducir por la propuesta de liberalización de culturas e identidades colectivas que propone Kymlicka ${ }^{68}$.

Asentado así el orden jurídico y político sobre la firme base de la dignidad humana, es forzoso, en segundo término, reconocer, y no sólo reconocer, sino también proclamar, garantizar y proteger eficazmente con medios jurídicos y políticos, los derechos humanos que son inherentes a dicha dignidad y dimanantes de ella.

Por supuesto que los derechos humanos son susceptibles de muy diversas formalizaciones como, de hecho, se aprecia a la vista de las distintas declaraciones y tablas que de los mismos ofrecen las Constituciones y Tratados Internacionales al respecto. Tampoco hay que negar que la determinación, reconocimiento, nivel de garantía y protección, así como su propio ámbito e interpretación no es igual en todas las culturas. Pero esta constatación no puede llevar a relativizarlos y mucho menos a reducirlos a una peculiar forma -la occidental- de ver el mundo. La razón es los derechos humanos no son emanación de una cultura determinada por lo mismo que tienen su fundamento en y derivan de la estructura óntica profunda de la persona humana y de ahí que, aunque sean susceptibles de diversas formalizaciones, resultan esencialmente universales.

Ahora bien, esto dicho, entiendo aquí por derechos humanos- a efectos de sostener que los mismos deben imponerse por encima de cualquier religión o ideología identitaria- el corpus doctrinal, legislativo y jurisprudencial que los determina, reconoce, garantiza, protege e interpreta en el contexto nacional de las Constituciones de las grandes democracias con tradición democrática y en el ámbito internacional de las declaraciones y tratados suscritos por las mismas que los formalizan y de la jurisprudencia independiente que los interpreta.

Una especial atención merece en este sentido la libertad religiosa, pues resulta crucial entender que este derecho humano exige, ciertamente, considerar por igual a todas las religiones, no obligar a nadie a profesar una de ellas ni impedir que alguien

${ }^{66}$ Cfr. KHUN, Thomas S., La estructura de las revoluciones científicas, Madrid, Fondo Cultura Económica, 1962.

${ }^{67}$ HUNTIGTON, P., El choque de civilizaciones..., op, cit., especialmente pag. 30.

${ }^{68}$ KYMLINCKA, W., Ciudadanía multicultural, Barcelona, Paidos, 1996. 
abandone la de su elección, pero que, con la misma certidumbre, también exige a todos que respeten los derechos humanos en sus manifestaciones religiosas externas.

Otro tanto cabe decir del derecho humano de libertad lingüística que exige que cada uno pueda usar su propia lengua, que una lengua no se imponga obligatoriamente a las demás y que todas se preserven como valores culturales e identitarios, sin perjuicio de incentivar el conocimiento de las lenguas universales de comunicación ${ }^{69}$.

Por lo que atañe al derecho de participación política, la identidad puede ser aplastada por la ley de la mayoría, por tanto se impone moderar ésta con mecanismos de defensa y preservación de los derechos de las minorías mediante fórmulas imaginativas como, por ejemplo, el sistema de cuotas proporcionales por comunidades que se ha ensayado en lugares conflictivos como Bosnia o Irlanda del Norte e incluso en la propia estructura central de la Unión Europea, de suerte que las instituciones de elección democrática o selección por mérito y capacidad sólo jueguen dentro de cada cupo de cuotas. Pero caben también otros métodos, como el de turnos, las reservas electorales (asegurar un número mínimo de representantes a ciertos distritos identitarios), etc. Todas estas fórmulas deben ser consensuadas democráticamente, y ese consenso debe reputarse constitucional y protegido mediante la técnica de las garantías institucionales.

En suma, hay que adecuar la democracia para que pueda responder bien a los problemas identitarios y, para ello, debe profundizarse más en la dinámica de los derechos humanos. En efecto, los derechos humanos exigen respetar todas las identidades pero, dentro de cada una, exigen que no deban ser respetadas más tradiciones y pertenencias que las que resulten respetables con arreglo a las exigencias de los propios derechos humanos. Aquí no hay parvedad de materia y debemos sostener con claridad que todo elemento identitario que no se acomode a las exigencias de los derechos humanos debe desaparecer y ser suprimido, por tradicional y venerable que sea, incluso aquellos que el grupo identitario correspondiente afirme como esenciales, irrenunciables o de fundación divina. Así se hizo con la institución de la esclavitud, del sufragio restringido y tantos otros elementos ancestrales que resultan incompatibles con los derechos humanos.

Estoy persuadido de que sólo lograremos asentar una convivencia pacífica en los distintos ámbitos en que se estructura el mundo si la asentamos sobre una identidad compartida con las de otras muchas personas y comunidades.

Logroño, Mayo de 2002.

${ }^{69}$ Parece claro que hay que tender a que cada uno conozca su propia lengua materna (que será siempre su lengua intra-sistémica), pero también un idioma universal (que será su lengua inter-sistémica) e incluso sería deseable que se poseyera otra lengua de libre elección personal, que sería la lengua sistémica o del corazón. De esta suerte se permitiría una adecuada sinapsis entre los sistemas lingüísticos. Mientras tanto, creo con A. Malouff que no queda otra solución que traducir y traducir. 